\title{
Potential of Lactic Acid Bacteria Isolated From Different Forages as Silage Inoculants for Improving Fermentation Quality and Aerobic Stability
}

\author{
Melisa Puntillo ${ }^{1}$, Mónica Gaggiotti ${ }^{2}$, Juan Martín Oteiza ${ }^{3}$, Ana Binetti ${ }^{1}$, Ariel Massera ${ }^{2}$ \\ and Gabriel Vinderola ${ }^{1 *}$
}

1 Instituto de Lactología Industrial (CONICET-UNL), Facultad de Ingeniería Química, Universidad Nacional del Litoral, Santa Fe, Argentina, ${ }^{2}$ Laboratorio de Calidad de Leche y Agroindustria, INTA EEA Rafaela, Santa Fe, Argentina, ${ }^{3}$ Centro de Investigación y Asistencia Técnica a la Industria, Río Negro, Argentina

\section{OPEN ACCESS}

Edited by:

Andrea Gomez-Zavaglia, National University of La Plata,

Argentina

Reviewed by:

Lorenzo Siroli,

University of Bologna, Italy

Lucia Vannini,

University of Bologna, Italy

Diana Di Gioia,

University of Bologna, Italy

Flaviano Martins,

Federal University of Minas Gerais,

Brazil

Laura Maria Bruno,

Embrapa Agroindústria Tropical, Brazil

*Correspondence:

Gabriel Vinderola

gvinde@fiq.unl.edu.ar

Specialty section:

This article was submitted to

Food Microbiology,

a section of the journal

Frontiers in Microbiology

Received: 23 July 2020 Accepted: 13 November 2020 Published: 08 December 2020

Citation:

Puntillo $M$, Gaggiotti $M$ Oteiza JM, Binetti A, Massera A and Vinderola G (2020) Potential of Lactic Acid Bacteria Isolated From Different

Forages as Silage Inoculants for Improving Fermentation Quality

and Aerobic Stability.

Front. Microbiol. 11:586716. do: 10.3389/fmicb.2020.586716
We aimed at isolating lactic acid bacteria $(\llcorner A B)$ from different plant materials to study their crossed-fermentation capacity in silos and to find strains able to confer enhanced aerobic stability to silage. A total of 129 LAB isolates were obtained from lucerne (alfalfa), maize, sorghum, ryegrass, rice, barley, canola, Gatton panic, Melilotus albus, soy, white clover, wheat, sunflower, oat, and moha. Four Lactiplantibacillus plantarum subsp. plantarum strains (isolated from oat, lucerne, sorghum, or maize) were selected for their growth capacity. Identity (16S sequencing) and diversity (RAPD-PCR) were confirmed. Fermentative capacity (inoculated at 104 $, 10^{5}, 10^{6}, 10^{7} \mathrm{CFU} / \mathrm{g}$ ) was studied in maize silage and their cross-fermentation capacity was assessed in oat, lucerne, sorghum, and maize. Heterofermentative strains with the highest acetic acid production capacity conferred higher aerobic stability to maize silages. Regardless the source of isolation, $L$. plantarum strains, inoculated at a rate of $10^{6} \mathrm{CFU} / \mathrm{g}$, were effective to produce silage from different plant materials. From more than 100 isolates obtained, the application of a succession of experiments allowed us to narrow down the number of potential candidates of silage inoculants to two strains. Based on the studies made, L. plantarum LpM15 and Limosilactobacillus fermentum LfM1 showed potential to be used as inoculants, however further studies are needed to determine their performance when inoculated together. The former because it positively influenced different quality parameters in oat, lucerne, sorghum, and maize silage, and the latter because of its capacity to confer enhanced aerobic stability to maize silage. The rest of the strains constitute a valuable collection of autochthonous strains that will be further studied in the future for new applications in animal or human foods.

Keywords: lactic acid bacteria, silage, inoculant, stability, fermentation

\section{INTRODUCTION}

Preserved forages, such as silages, are used as a major proportion of the diet fed to dairy cows and other cattle in many milk and meat producing countries. Lactiplantibacillus plantarum subsp. plantarum (formerly Lactobacillus plantarum, Zheng et al., 2020), Pediococcus pentosaceus and Enterococcus faecium are probably the homofermentative lactic acid bacteria (LAB) species most 
intensively used as silage inoculants (Ogunade et al., 2019). When silos are opened and the ensiled material is exposed to the air, a deterioration process may begin, mainly by lactate assimilating yeasts, which leads to an increase in the silage temperature followed by an increase in the $\mathrm{pH}$ values, allowing the growth of other aerobic microorganisms and further deterioration (Kung et al., 2018). In order to overcome this problem, heterofermentative LAB, mainly Lentilactobacillus buchneri subsp. buchneri, have been used for more than two decades so far for silage preservation (Filya, 2003; Schmidt et al., 2009). In common daily use of silage inoculants, some issues related to the concentration of viable LAB to be applied, the efficacy of strains isolated from plant materials different to the one to be fermented and the possibility of using heterofermentative species other than L. buchneri for enhanced aerobic stability, are of interest. Isolation of novel LAB strains for application in silage has been a common practice over the years but it is still an activity with current importance around the globe (dos Santos Leandro et al., 2020; Paradhipta et al., 2020; Tanizawa et al., 2020), due to the interest in collecting diverse strains for future applications not only as silage inoculants but also in other plant-based food for animals and humans use (Wuyts et al., 2020). In Argentina, the ensiling market is highly dominated by products manufactured abroad with foreign strains, being the European countries the ones leading the market with a share of $44 \%$ of the global silage additives market (Fabiszewska et al., 2019). The availability of strains locally sourced will foster the development of products that may fuel our compromised economy. In addition, the key inoculant companies in the market are expanding their business units in various geographical areas, focusing on agreements and partnerships with local players and distributors, including researchers, introducing new effective products through investments in R\&D (Fabiszewska et al., 2019). Then, the importance of local research and evaluation of new strains adapted to the fermentative process of local forages was recently highlighted (Amaral et al., 2020).

The aim of this work was to isolate LAB strains from different plant materials to study their crossed-fermentation capacity in silos and to find novel candidates to promote aerobic stability to be exploited in the southern cone. To the best of our knowledge, this is the study where the most diverse variety of forages was used within the same work (15 different plant materials), to isolate new $\mathrm{LAB}$ strains for preliminary characterization and future exploitation.

\section{MATERIALS AND METHODS}

\section{Sample Collection}

The following plant materials were sampled: lucerne (alfalfa: Medicago sativa), maize (Zea mays), sorghum (Sorghum spp.), ryegrass (Lolium perenne), rice (Oryza sativa), barley (Hordeum vulgare), canola, Gatton panic, Melilotus albus, soy (Glycine max), white clover (Trifolium repens), wheat (Triticum spp.), sunflower (Helianthus annuus), oat (Avena sativa), and moha (Setaria italica). Samples were obtained in duplicates from local farmers of Santa Fe Province (cities of Esperanza, Rafaela, Cavour, Grutly,
Frank, Pozo Borrado, and Candioti) and Buenos Aires Province (cities of Pergamino and Tandil) during 2016. Samples (1 Kg) were harvested at an adequate physiological state for silage, indicated by the local farmers, and immediately transported to the laboratory, where they were chopped to approximately $1 \mathrm{~cm}$ using a laboratory forage chopper (BIMG-METVISA, Brazil), except for maize and sorghum, which were chopped at the farmer's place, by a farming chopper. After chopping, the material was ensiled using a small-scale system of silage fermentation, as follows: approximately $500 \mathrm{~g}$ portions of each material were packed into polyethylene bags (Cryovac: BB4LA), sealed with a vacuum sealer (Turbovac, Bosch) and incubated at $34^{\circ} \mathrm{C}$ (MiLab, SPX-250 B III, China). Samples were allowed to ferment until a $\mathrm{pH}$ lower than 4.5 was achieved (Orion 3 Star, Thermo Fisher Scientific, Beverly, MA, United States), measuring $\mathrm{pH}$ in several replicates of the ensiled material, for successive measurements until pH 4.5 was observed.

\section{Isolation of LAB}

Figure 1 shows the flow chart of the isolation, selection, and characterization processes used in this study. A sample (10 g) of the fermented plant material was aseptically homogenized with $90 \mathrm{ml}$ of sterile $0.85 \% \mathrm{NaCl}$ solution in a sterile plastic bag (Nasco WHIRL-PACK, United States) using a stomacher (3 min, high speed, three cycles). Supernatants were serially diluted with peptone water $(0.1 \% \mathrm{w} / \mathrm{v}$, Britania, Buenos Aires, Argentina) and surface-plated on MRS agar (Biokar, Beauvais, France). Plates were incubated (aerobiosis, $34^{\circ} \mathrm{C}, 48 \mathrm{~h}$ ). Colonies presenting typical LAB morphology (immersion microscopy, $1000 \times$ ) were picked-up and streaked on MRS agar. Gram-staining, mobility, catalase activity, spore-forming capacity, and gas production from glucose in MRS broth (Dürham tubes) were assessed using standard procedures. Presumptive homo and heterofermentative $\mathrm{LAB}$ isolates were frozen-stored (at $-20^{\circ} \mathrm{C}$ and $-70^{\circ} \mathrm{C}$ ) in MRS$20 \%(\mathrm{v} / \mathrm{v})$ glycerol broth. The term presumptive was used until proper identification was carried out.

\section{Identification of Isolates}

Preliminary identification was carried out according to the protein and peptide profile by means of Matrix-Assisted-LaserDesorption-Ionization-Time-of-Flight Mass Spectrometry (MALDI-TOF MS), using an Axima Performance mass spectrometer (Shimadzu Scientific Instruments, United States) in conjunction with the commercial Spectral Archive And Microbial Identification System (SARAMIS) database. Analyses were performed according to the manufacturer's instructions using the direct smear technique, by the Mass Spectroscopy Laboratory from the Biological Sciences and Biochemistry Faculty of the National University of Litoral (Santa Fe, Argentina).

\section{Growth Kinetics and Selection of L. plantarum Strains Growth Kinetics in Forage-Based Medium}

Forage-based media (FBM) were prepared with lucerne, oat, sorghum, and maize (ABM, OBM, SBM, MBM, respectively). Fresh (non-fermented) samples of chopped lucerne, oat, 


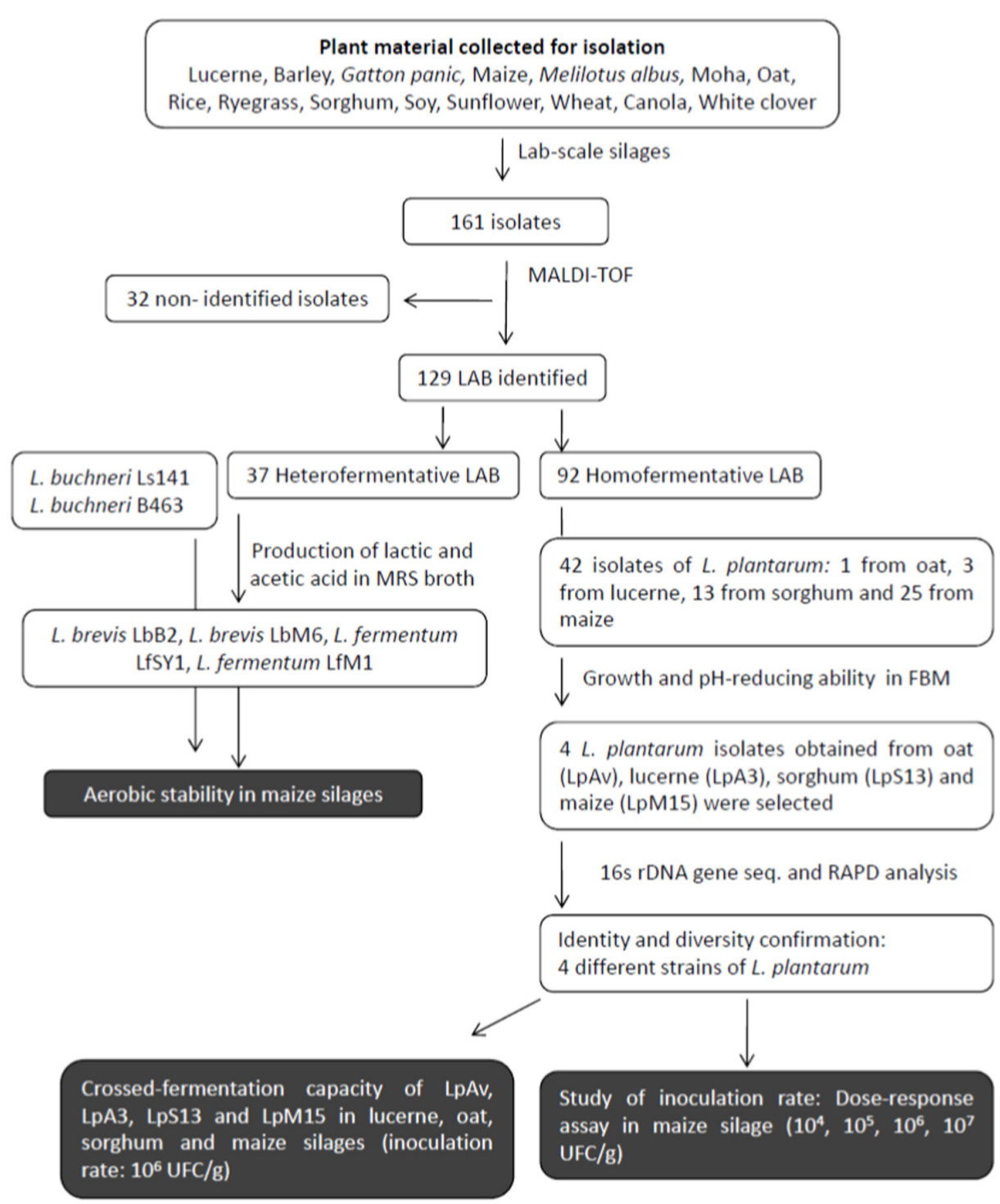

FIGURE 1 | Flow chart of the isolation, selection, and characterization process.

sorghum, or maize were mixed (1:10) with distilled water and homogenized (stomacher, $3 \mathrm{~min}$, high speed, three cycles). The suspension was filtered (filter papers Quanty JP41 Faixa Preta, Londrina, PR, Brazil) and centrifuged $\left(5000 \times g, 10 \mathrm{~min}, 8^{\circ} \mathrm{C}\right)$. The $\mathrm{pH}$ of the supernatant was adjusted to 6.5 with $1 \mathrm{M}$ $\mathrm{NaOH}$, aliquoted and autoclaved $\left(121^{\circ} \mathrm{C}, 15 \mathrm{~min}\right)$. Each FBM was inoculated $(1 \% \mathrm{v} / \mathrm{v})$ with an overnight culture (MRS broth, adjusted to $1 \times 10^{8} \mathrm{CFU} / \mathrm{ml}$ ) of each $L$. plantarum strain isolated from oat, lucerne, sorghum, and maize. All isolates were tested at this stage. Cultures were previously washed twice with PBS (phosphate buffered saline solution, $\mathrm{pH}$ 7.4) in order not to carry over nutrients from MRS broth. Inoculated FBM (ca. $10^{6} \mathrm{CFU} / \mathrm{ml}$ ) were distributed (300 $\mu \mathrm{l} /$ well) in 96well microplates (Thermo Scientific Multiskan FC Microplate Photometer) and incubated at $34^{\circ} \mathrm{C}$ in aerobiosis. Optical density $\left(\mathrm{OD}_{560 \mathrm{~nm}}\right)$ was measured every $30 \mathrm{~min}$ during $18 \mathrm{~h}$. In parallel, a sample of inoculated FBM (ca. $10^{6} \mathrm{CFU} / \mathrm{ml}$ ) was incubated in $5 \mathrm{ml}$ test tubes (aerobiosis, $34^{\circ} \mathrm{C}$ for 24 and $48 \mathrm{~h}$ ). $\mathrm{OD}_{560 \mathrm{~nm}}$, $\mathrm{pH}$ and cell counts (MRS agar) were performed. Each strain was assayed in independent triplicates. Results were expressed as $\left(\Delta \log _{10} \mathrm{CFU} / \mathrm{ml}\right)$, where $\Delta$ is the difference between cell counts after 24 or $48 \mathrm{~h}$ with respect to the initial count.

\section{Identity Confirmation}

Total DNA of selected L. plantarum strains was extracted from overnight cultures ( $18 \mathrm{~h}$ ) by using GenElute Bacterial Genomic DNA kit (Sigma, St. Louis, MO, United States) according to the manufacturer's instructions. Purified DNA samples were stored at $-20^{\circ} \mathrm{C}$ until use. The identity of isolates was analyzed by amplifying, sequencing and comparing a 1500 bp fragment within their 16S rRNA gene (pA: AGA GTT TGA TCC TGG CTC AG, pH: AAG GAG GTG ATC CAG CCG CA) 
(Edwards et al., 1989). All PCR reactions were performed using $2 \mu \mathrm{l}$ of diluted (1:50) DNA as template, $2.5 \mathrm{U}$ Taq DNA polymerase (GE Helathcare, Little Chalfont, United Kingdom), $200 \mu \mathrm{M}$ dNTPs (GE Healthcare) and $100 \mathrm{nM}$ each primer (Sigma-Genosys, The Woodlands, TX, United States) in a final volume of $50 \mu \mathrm{l}$. Amplifications were performed in a GeneAmp PCR System (Applied Biosystem, Foster City, CA, United States) under the following conditions: $3 \mathrm{~min}$ at $94^{\circ} \mathrm{C}, 36$ cycles of denaturation at $94^{\circ} \mathrm{C}$ for $1 \mathrm{~min}, 2 \mathrm{~min}$ annealing at $51^{\circ} \mathrm{C}$ and 2 min extension at $72^{\circ} \mathrm{C}$, and a final step of $7 \mathrm{~min}$ at $72^{\circ} \mathrm{C}$. The PCR products were separated on $0.8 \%(\mathrm{w} / \mathrm{v})$ agarose gels in TBE buffer, stained with GelRed (Biotium, Hayward, CA, United States) and visualized under UV light. Amplicons were purified with MicroSpin Columns (GE Healthcare) and their nucleotide sequences were determined by primer extension at the DNA Sequencing Service of Macrogen (Seoul, South Korea). The identity of isolates was checked by nucleotide-nucleotide BLAST of the NCBI database ${ }^{1}$.

\section{RAPD Analysis}

The genotypic diversity of selected L. plantarum isolated was analyzed by RAPD-PCR, using two arbitrary primers, B10 (5' CTGCTGGGAC - $3^{\prime}$ ) and M13 (5'- GAGGGTGGCGGTTCT $3^{\prime}$ ), and amplification conditions were primer-dependent (Giraffa et al., 2004; Binetti et al., 2007).

\section{Lab-Scale Silage Preparation}

The following general procedure for micro-silos manufacture was used along this work to study the ensiling capacity of selected LAB strains. Overnight cultures of the strains used in the experiments described below were obtained in MRS broth, centrifuged $\left(5000 \times g, 15 \mathrm{~min}, 8^{\circ} \mathrm{C}\right)$, washed twice with PBS $(\mathrm{pH}$ 7.2) and resuspended in $\mathrm{NaCl} 0.85 \%(w / v)$. Silages were made using the corresponding fresh-cut forage, employing a small-scale system for silage preparation (Burns et al., 2018). Growth stage at harvesting, for each forage, was the proper one for ensiling according to the farmer that provided the material. Forage was chopped (length of $17 \mathrm{~mm}$ ) by a precision chop forage harvester (Claas Jaguar, Claas Group, Harsewinkel, Germany). Lucerne was left to wilt for $4 \mathrm{~h}$ before chopping. Chopped material was transported in plastic bags within $1 \mathrm{~h}$ of chopping to the laboratory and processed immediately. Sixty kilogram of chopped forage were sprayed at a rate of $20 \mathrm{ml} / \mathrm{kg}$ of fresh forage, with the suspension of the strain at different concentrations (depending on the experimental design: 2.6.1, 2.6.2, or 2.7.2). Control (noninoculated) samples were sprayed with the same amount of $\mathrm{NaCl}$ $0.85 \% \mathrm{w} / \mathrm{v}$, which was used for preparing the strains suspensions. All treatments were applied at the same time, thanks to the aid of the laboratory personnel. Inoculated plant-material was distributed into $1 \mathrm{~kg}$ portions in polyethylene bags in triplicates for each sampling point (Cryovac: BB4LA) and vacuum-sealed (Turbovac, Bosch) to become a micro-silo. Micro-silos were kept at $25^{\circ} \mathrm{C}$ for different periods, depending on the specific assay (indicated below).

\footnotetext{
${ }^{1}$ https://blast.ncbi.nlm.nih.gov/Blast.cgi
}

\section{L. plantarum Strains as Inoculants in Lab-Scale Silages}

\section{Dose-Response in Maize Silage}

Four L. plantarum strains (one isolated from each substrate) were selected based on their growth kinetics on FBM. L. plantarum LpAv, LpA03, LpS13, and LpM15 were isolated from oat, lucerne, sorghum, and maize, respectively. Fresh maize silages (in triplicate, for each sampling day) were prepared as described before. The strains were inoculated at a rate of $10^{4}, 10^{5}, 10^{6}$, and $10^{7} \mathrm{CFU} / \mathrm{g}$ of fresh plant material. Control samples were sprayed with $\mathrm{NaCl} 0.85 \% \mathrm{w} / \mathrm{v}$. Total $\mathrm{LAB}$ count and $\mathrm{pH}$ were determined in triplicates after $0,24,48,72 \mathrm{~h}$, and 30 days of fermentation.

\section{Crossed-Fermentation Capacity in Lucerne, Oat, Sorghum, and Maize Silage}

Lucerne, oat, sorghum, and maize silages were prepared as described above using four L. plantarum strains (LpAv, LpA03, LpS13, and LpM15). Each strain was used on each plant material (crossed-fermentation). Strains were inoculated at a rate of $1 \times 10^{6} \mathrm{CFU} / \mathrm{g}$ of fresh chopped material. Control was sprayed with the same volume of $\mathrm{NaCl} 0.85 \%$ w/v. Microbiological analyses and $\mathrm{pH}$ determinations were carried out at different days of storage, depending on the forage: 0,2 , and 30 days (oat); 0,3 , and 30 days (lucerne); $0,1,3$, and 30 days (sorghum and maize), as suggested by the farmers that provided each material. Total LAB were enumerated in triplicates MRS agar $\left(34^{\circ} \mathrm{C}, 48 \mathrm{~h}\right.$, aerobiosis) and yeasts and molds in chloramphenicol glucose agar (Biokar, Beauvais, France) $\left(25^{\circ} \mathrm{C}, 7\right.$ days, aerobiosis).

The following parameters were assessed, in triplicates, at the beginning and after 30 days of fermentation: Dry Matter (\% DM; PROMEFA-v2 AOAC, $1990 \mathrm{~N}^{\circ} 130.15$ and $\left.\mathrm{N}^{\circ} 167.03\right)$, Crude Protein (\% CP; AOAC, $1998 \mathrm{~N}^{\circ}$ 976.05), Ash (\% Ash, AOAC 1990 N1C 942.05), Acid Detergent Fiber (\% ADF; ANKOM Method validated with ISO13906:2008), Neutral Detergent Fiber (\% NDF; ANKOM Method validated with ISO16472:2006), Acid Detergent Lignin (\% LDA; PROMEFA-v2, ANKOM), Ether Extract (\% EE; AOAC $1999 \mathrm{~N}^{\circ}$ 920.39). Ammonia Nitrogen/Total Nitrogen ( N NH/N T; Blain and Urtunette, 1954) was quantified after different days of fermentation: 2 and 30 days (oat); 3 and 30 days (lucerne); 1 and 30 days (sorghum and maize). Analyses were performed by the Laboratorio de Forrajes, Instituto Nacional de Tecnología Agropecuaria (INTA, Rafaela, Santa Fe, Argentina). Analyses were carried out in triplicate.

\section{Selection of Heterofermentative LAB for Enhanced Aerobic Stability Lactic and Acetic Acid Quantification in Heterofermentative Strains}

The 37 heterofermentative LAB isolated in this study were inoculated $(1 \% \mathrm{v} / \mathrm{v}$, in triplicates) on $10 \mathrm{ml}$ of MRS broth supplemented with $0.1 \%$ (w/v) cysteine. L. buchneri Ls141 and 463 were used as external reference strains. L. buchneri Ls141 had been isolated from maize silage in a previous work (Burns et al., 2018) and it is currently used in a commercial inoculant in Argentina. L. buchneri 463 was isolated from a spoiled 
commercial tomato sauce (the strain was kindly provided by Dr. Juan Martín Oteiza). After $72 \mathrm{~h}$ of anaerobic incubation at $34^{\circ} \mathrm{C}$, cultures were centrifuged $\left(5000 \times g, 10 \mathrm{~min}, 8^{\circ} \mathrm{C}\right)$ and supernatans were filtered $(0.45 \mu \mathrm{m}$ cellulose nitrate filter, Sartorius, Germany). Quantification of lactic and acetic acids was performed by HPLC. Chromatographic separation was carried out isocratically at $65^{\circ} \mathrm{C}$ with a mobile phase of $10 \mathrm{mM}$ $\mathrm{H}_{2} \mathrm{SO}_{4}$ at a flow rate of $0.6 \mathrm{ml} / \mathrm{min}$ on an Aminex HPX-87H column $(300 \times 7.8 \mathrm{~mm})$ equipped with a cation $\mathrm{H}+$ microguard cartridge (Bio-Rad Laboratories, United States). The supernatant of cultures after centrifugation was diluted 1:3 with $10 \mathrm{mM}$ $\mathrm{H}_{2} \mathrm{SO}_{4}$, filtered through $0.45 \mu \mathrm{m}$ membranes (Millex, Millipore, Brazil) and injected into the chromatograph, using a loop of $60 \mu$ l. HPLC equipment consisted of a quaternary pump, an online degasser, a column oven, a UV-visible detector (all Series 200) and a refractive index detector thermostatised at $35^{\circ} \mathrm{C}$ (Series Flexar) (Perkin Elmer, United States). The UV detector was set at $210 \mathrm{~nm}$ for the detection of organic acids. Data were collected and processed on a computer with the software Chromera (Perkin Elmer).

\section{Aerobic Stability in Maize Silage}

In order to study the capacity of selected heterofermentative strains to control yeasts and molds, fresh-cut maize silages were prepared as described before. Limosilactobacillus fermentum LfSY and LfM1, Levilactobacillus brevis LbB2 and LbM6 and L. buchneri Ls141 and 463 were inoculated at a rate of $1 \times 10^{6} \mathrm{CFU} / \mathrm{g}$ of fresh chopped material. A control (noninoculated) was included. The $\mathrm{pH}$ values and $\mathrm{LAB}$ counts were determined, in triplicates, at the beginning $(t=0)$ and after 90 days of fermentation. Dry Matter (DM) was determined as indicated above. After 90 days, silages were opened and aerobic stability was determined according to Burns et al. (2018) in a room were temperature was controlled at $21 \pm 1^{\circ} \mathrm{C}$, in duplicates. Aerobic stability was defined as the time necessary for the internal temperature of silage to increase $2^{\circ} \mathrm{C}$ above room temperature.

\section{Statistical Analyses}

All measurements were performed in triplicate and the results were presented as mean \pm standard deviation. Data were analyzed using the one-way ANOVA procedure of SPSS 15.0 software (SPSS Inc., Chicago, IL, United States). The differences between means were detected by Tukey or Dunnett test, depending whether comparison was among all groups (Tukey) or compared to the control group (Dunnett). Differences were considered statistically significantly different when $p<0.05$.

\section{RESULTS}

\section{Isolation and MALDI-TOF Identification of LAB From Different Plant Material}

Fifty-one samples from 15 forage crops were processed. Except from Canola, a total of 161 presumptive LAB isolates were obtained from the other 14 forage crops. Table 1 shows the identity (by MALDI-TOF) and origin of the 129 isolates identified as belonging to different species of the LAB group, the rest of the isolates were not identified by MALDI-TOF, and were no longer considered for this study. L. pentosus/plantarum was the homofermentative species for which the highest number of isolates were obtained. The most frequently isolated heterofermentative species was L. brevis, which was found in 6 out of 14 plant materials studied.

\section{Growth Capacity of L. plantarum in Forage-Based Medium: Selection and Identity Confirmation of Strains for Further Studies}

The growth ability of L. plantarum strains isolated from lucerne, oat, sorghum or maize was assessed in the same FBM from which isolates were obtained: ABM, OBM, SBM, and MBM. Growth kinetics showed that the different isolates obtained from the same plant material displayed different growth capacity in laboratoryprepared media (growth kinetics, pH, and O.D. not shown). Figure 2 shows the differences in cell counts after 24 and $48 \mathrm{~h}$ of incubation in each FBM, compared to counts at time zero $\left(\Delta \log _{10}\right.$ $\mathrm{CFU} / \mathrm{ml}$ ). Most isolates grew from 1 to 1.5 log orders, while some isolates obtained from maize were able to reach the expected $2 \log$ orders of growth in MBM (as 1\% v/v inoculum was used). After $24 \mathrm{~h}$ of culture, loss of cell viability was observed in most cases.

Changes in the $\mathrm{pH}$ of the inoculated media showed the ability of all L. plantarum isolates to ferment the corresponding FBM. In OBM, LpAv dropped the $\mathrm{pH}$ from 6.55 to $5.80(24 \mathrm{~h})$ and 4.89 (48 h). In ABM, LpA1, LpA2, and LpA3 decreased the pH from 6.26 to $5.80-5.95$ after $24 \mathrm{~h}$ of fermentation, and there was no further $\mathrm{pH}$ reduction after $48 \mathrm{~h}$ of incubation. L. plantarum strains isolated from sorghum decreased the $\mathrm{pH}$ of SBM from 6.47 to $3.93-4.03(24 \mathrm{~h})$ and $3.78-3.90$ (48 h). L. plantarum strains obtained from maize reduced $\mathrm{pH}$ values of the MBM from 6.19 to $3.91-4.25$ after $24 \mathrm{~h}$, and then a negligible additional $\mathrm{pH}$ drop after $48 \mathrm{~h}$ of incubation was observed. $\mathrm{pH}$ values of control (non-inoculated FBM) remained unchanged along incubation for 48 h. Due to their capacity to low down pH, LpAv, LpA3, LpS13, and LpM15 were selected for further studies. These isolates were confirmed to belong to the species L. plantarum by sequencing of the 16S rRNA gene. This data are publicly available: https://www. ncbi.nlm.nih.gov/nuccore/MT799877 (LpA3), https://www.ncbi. nlm.nih.gov/nuccore/MT798595 (LpAv), https://www.ncbi.nlm. nih.gov/nuccore/MT798596 (LpS13), https://www.ncbi.nlm.nih. gov/nuccore/MT799876 (LpM15). RAPD profiling confirmed that these isolates were, indeed, different strains (Supplementary Figure 1).

In order to study the capacity of L. plantarum strains to ferment different plant materials (others than the one from where they were isolated), crossed-growth kinetics and cell counts were performed for the four L. plantarum LpAv, LpA3, LpS13, and LpM15 in OBM, ABM, SBM, and MBM. Similar growth kinetics (figures not shown) were observed for the four strains on each plant material, but different cell counts were observed after 24 and $48 \mathrm{~h}$ of growth in each plant material (Figure 3). In terms of cell counts, the higher growth was supported by ABM ( $>1.6$ $\left.\Delta \log _{10} \mathrm{CFU} / \mathrm{ml}\right)$, followed by MBM $\left(1.2-1.4 \Delta \log _{10} \mathrm{CFU} / \mathrm{ml}\right)$, being L. plantarum A3 the strain that displayed the highest 
TABLE 1 | Identity (MALDI-TOF MS) of LAB isolates derived from plant material.

\begin{tabular}{|c|c|c|}
\hline Plant material ${ }^{a}$ & Isolated species & Isolate identification code \\
\hline & Pediococcus acidilactici & $\mathrm{PaA} 1, \mathrm{PaA} 2, \mathrm{PaA} 3, \mathrm{PaA} 4$ \\
\hline \multirow[t]{4}{*}{ Barley (5) } & L. brevis & LbB1, LbB2, LbB3 \\
\hline & Lactococcus garvieae & LgB1, LgB2 \\
\hline & Enterococcus hirae & EB1, EB2 \\
\hline & E. faecium & EB4 \\
\hline Gatton panic (2) & Enterococcus durans & EG1 \\
\hline \multirow[t]{7}{*}{ Maize (11) } & L. pentosus/plantarum & $\begin{array}{l}\text { LpM0, LpM1, LpM2, LpM3, LpM4, LpM5, LpM6, LpM7, LpM8, LpM9, LpM10, LpM11, } \\
\text { LpM12, LpM13, LpM14, LpM15, LpM16, LpM17, LpM18, LpM19, LpM20, LpM21, } \\
\text { LpM22, LpM23, LpM24 }\end{array}$ \\
\hline & L. paracasei & LpaM1 \\
\hline & P. acidilactici & PaM1 \\
\hline & P. pentosaceus & PpM1, РpM2, РpM3 \\
\hline & Leuconostoc citreum & LciM1 \\
\hline & Weissella confusa & WcM1 \\
\hline & Lactobacillus sp. & LspM \\
\hline \multirow[t]{2}{*}{ Melilotus albus (1) } & L. pentosus/plantarum & LpML1 \\
\hline & P. pentosaceus & PpML1 \\
\hline Moha (1) & L. fermentum & LfMH \\
\hline \multirow[t]{2}{*}{ Oat (5) } & L. pentosus/plantarum & LpAv \\
\hline & L. paracasei & LcAv \\
\hline \multirow[t]{2}{*}{ Sorghum (6) } & L. pentosus/plantarum & LpS1, LpS2, LpS3, LpS4, LpS5, LpS6, LpS7, LpS8, LpS9, LpS10, LpS11, LpS12, LpS13 \\
\hline & L. brevis & LbS1 \\
\hline \multirow[t]{4}{*}{ Soy (2) } & L. pentosus/plantarum & LpSY1 \\
\hline & L. brevis & LbSY1 \\
\hline & L. fermentum & LfSY1, LfSY2, LfSY3, LfSY4 \\
\hline & P. acidilactici & PaSY1 \\
\hline \multirow[t]{2}{*}{ Sunflower (3) } & L. pentosus/plantarum & LpSF1 \\
\hline & E. hirae & EhSF1 \\
\hline \multirow[t]{3}{*}{ Wheat (3) } & L. pentosus/plantarum & LpW1, LpW2 \\
\hline & L. pseudomesenteroides & LeuW1, LeuW2 \\
\hline & Lactococcu lactis & LIW1 \\
\hline \multirow[t]{3}{*}{ White clover (3) } & L. pentosus/plantarum & LpWC1, LpWC2 \\
\hline & E. faecium & EfWC1, EfWC2 \\
\hline & Enterococcus sp. & EspWC1, EspWC2, EspWC3 \\
\hline
\end{tabular}

a The number between brackets indicates the number of samples analyzed.

variability in growth capacity among the four FBM assessed. LpS13 displayed the highest growth capacity whereas the growth of LpAv was significantly lower in the four media $(p<0.05)$, compared to LpS13, particularly in SBM.
In case of $\mathrm{pH}$ (Table 2), the selected strains were more effective for fermenting maize and sorghum when compared to oat and lucerne. Although statistical differences were observed among $\mathrm{pH}$ values, 

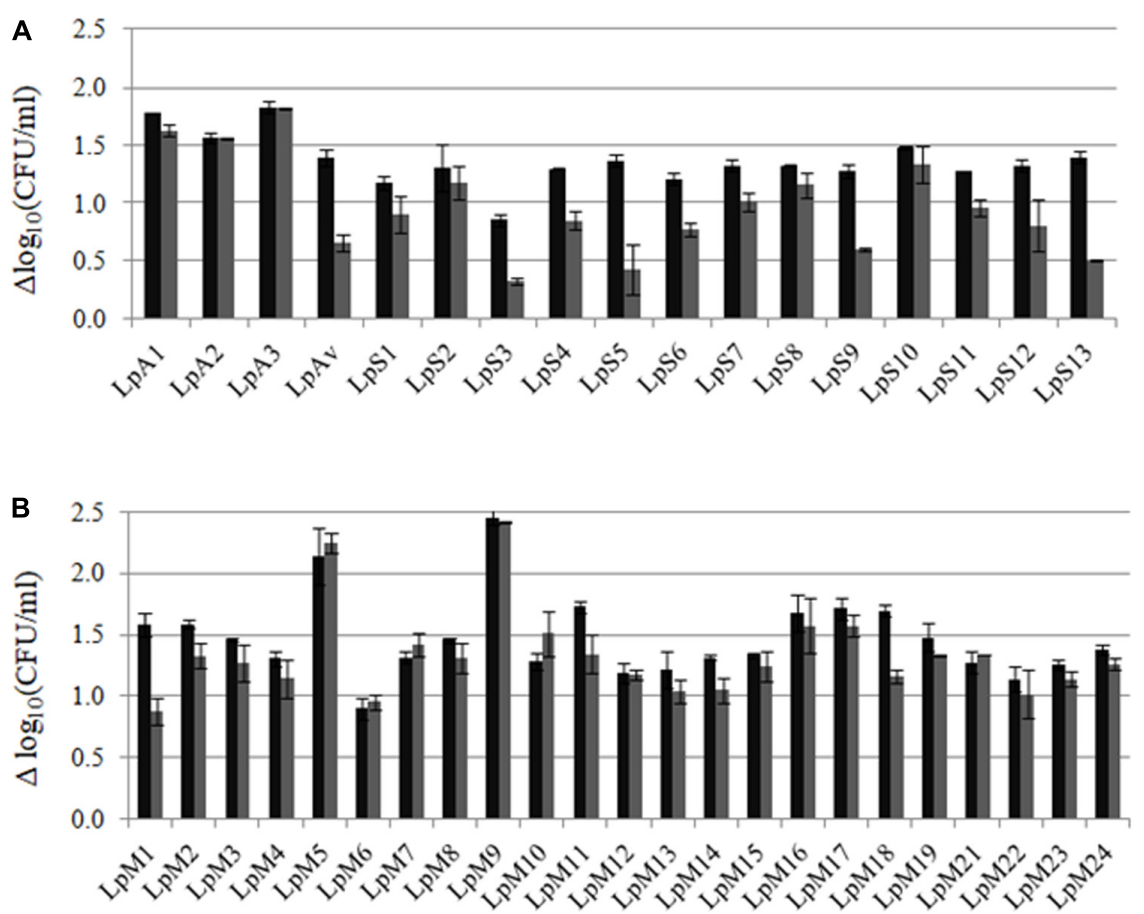

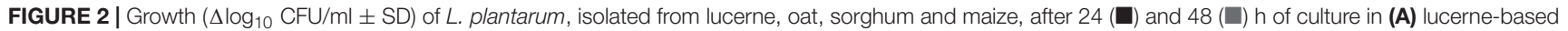
medium (LpA1-LpA3), oat-based medium (LpAv), sorghum-based medium (LpS1-LpS13) and (B) maize-based medium (LpM21-LpM24). Values are means ( $($ SD) of three repetitions.
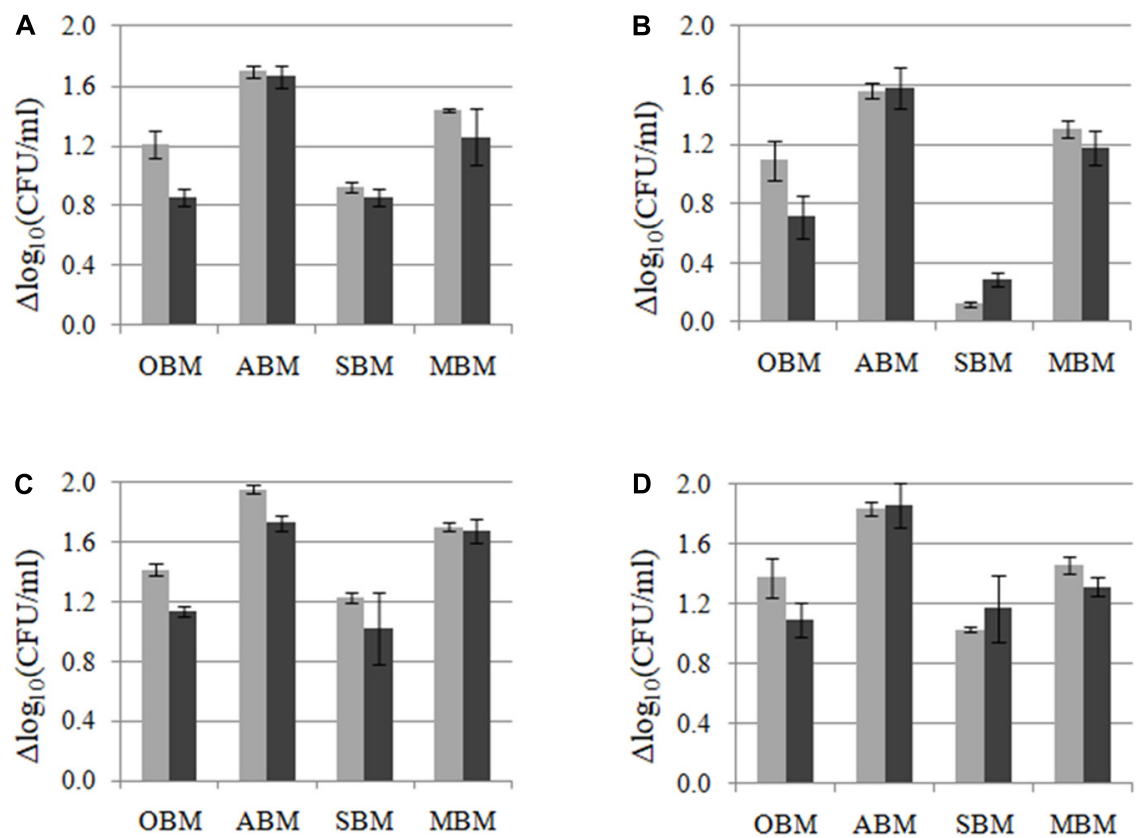

FIGURE 3 | Growth ( $\Delta \log _{10} \mathrm{CFU} / \mathrm{ml}$ ) of L. plantarum LpAv (A), LpA3 (B), LpS13 (C), and LpM15 (D) in oat (OBM), lucerne (ABM), sorghum (SBM), and maize based medium (MBM), after $24(\square)$ and $48 \mathrm{~h}(\mathbf{\square})$ of culture. Values are means $( \pm S D)$ of three repetitions. 
TABLE 2 | pH values of forage-based medium (FBM) inoculated with L. plantarum strains (LpAv, LpA3, LpS13, and LpM15) at the beginning and after 24, 48, and $72 \mathrm{~h}$ of incubation.

\begin{tabular}{|c|c|c|c|c|c|}
\hline \multirow[t]{2}{*}{ FBM } & \multirow[t]{2}{*}{ Strain name } & \multicolumn{4}{|c|}{ Time (h) } \\
\hline & & Before inoculation & 24 & 48 & 72 \\
\hline \multirow[t]{5}{*}{ Oat-based medium } & Control & $6.55 \pm 0.01$ & $6.56 \pm 0.01^{a}$ & $6.65 \pm 0.04^{a}$ & $6.64 \pm 0.01^{a}$ \\
\hline & LpAv & & $4.68 \pm 0.01^{b}$ & $4.92 \pm 0.02^{b, c}$ & $4.96 \pm 0.02^{b}$ \\
\hline & LpA3 & & $4.71 \pm 0.01^{c}$ & $4.91 \pm 0.04^{b}$ & $4.87 \pm 0.03^{c}$ \\
\hline & LpS13 & & $4.77 \pm 0.01^{d}$ & $5.01 \pm 0.04^{b, c}$ & $4.99 \pm 0.02^{b}$ \\
\hline & LpM15 & & $4.79 \pm 0.01^{d}$ & $5.02 \pm 0.01^{c}$ & $4.99 \pm 0.01^{b}$ \\
\hline \multirow[t]{5}{*}{ Lucerne-based medium } & Control & $6.20 \pm 0.01$ & $6.18 \pm 0.01^{a}$ & $6.27 \pm 0.02^{a}$ & $6.16 \pm 0.03^{a}$ \\
\hline & LpAv & & $5.77 \pm 0.01^{b}$ & $5.91 \pm 0.01^{b}$ & $5.88 \pm 0.03^{b}$ \\
\hline & LpA3 & & $5.68 \pm 0.01^{c}$ & $5.74 \pm 0.03^{c}$ & $5.74 \pm 0.02^{c}$ \\
\hline & LpS13 & & $5.68 \pm 0.01^{c}$ & $5.86 \pm 0.02^{b, c}$ & $5.82 \pm 0.02^{b}$ \\
\hline & LpM15 & & $5.78 \pm 0.01^{b}$ & $5.94 \pm 0.07^{b}$ & $5.96 \pm 0.02^{d}$ \\
\hline \multirow[t]{5}{*}{ Sorghum-based medium } & Control & $6.37 \pm 0.03$ & $6.44 \pm 0.04^{a}$ & $6.43 \pm 0.03^{a}$ & $6.38 \pm 0.03^{a}$ \\
\hline & LpAv & & $3.97 \pm 0.05^{b}$ & $3.98 \pm 0.04^{b}$ & $3.85 \pm 0.01^{b}$ \\
\hline & LpA3 & & $4.03 \pm 0.01^{b}$ & $3.96 \pm 0.01^{b}$ & $3.87 \pm 0.02^{b}$ \\
\hline & LpS13 & & $3.95 \pm 0.05^{b}$ & $3.94 \pm 0.02^{b}$ & $3.86 \pm 0.01^{b}$ \\
\hline & LpM15 & & $3.93 \pm 0.01^{b}$ & $3.95 \pm 0.01^{b}$ & $3.89 \pm 0.01^{b}$ \\
\hline \multirow[t]{5}{*}{ Maize-based medium } & Control & $6.20 \pm 0.03$ & $6.24 \pm 0.03^{a}$ & $6.20 \pm 0.02^{a}$ & $6.19 \pm 0.03^{a}$ \\
\hline & LpAv & & $3.93 \pm 0.01^{b}$ & $3.81 \pm 0.01^{b}$ & $3.74 \pm 0.02^{b}$ \\
\hline & LpA3 & & $4.03 \pm 0.01^{c}$ & $3.83 \pm 0.02^{b, c}$ & $3.74 \pm 0.01^{b}$ \\
\hline & LpS13 & & $4.07 \pm 0.01^{c}$ & $3.88 \pm 0.01^{c}$ & $3.77 \pm 0.02^{c}$ \\
\hline & LpM15 & & $4.04 \pm 0.01^{c}$ & $3.83 \pm 0.01^{b, c}$ & $3.78 \pm 0.02^{c}$ \\
\hline
\end{tabular}

Values are means $( \pm S D)$ of three repetitions. ${ }^{a, b},{ }^{c}$ Values with different superscripts differ significantly $(p<0.05)$ in each column for the corresponding time and forage.

these were very small and may be not relevant for practical purposes.

\section{Dose-Response of $L$. plantarum in Maize-Silage}

Lactiplantibacillus plantarum LpAv, LpA3, LpS13, and LpM15 were inoculated at four rates $\left(10^{4}, 10^{5}, 10^{6}\right.$, and $10^{7} \mathrm{CFU} / \mathrm{g}$ of fresh-chopped material) and fermentation was allowed to take place for 30 days. The $\mathrm{pH}$ values are shown in Figure 4. A statistical analysis (Dunnett test) was conducted after 1 day of fermentation. For LpAv, the dose of $10^{4} \mathrm{CFU} / \mathrm{g}$ produced no differences compared to control samples $(p=0.871)$, whereas $\mathrm{pH}$ achieved by the doses $10^{5}, 10^{6}$, and $10^{7} \mathrm{CFU} / \mathrm{g}$ were significantly lower compared to control $(p=0.014,<0.001$, and $<0.001$, respectively) and among them ( $p<0.001$, Tukey test). For LpA3, all doses induced a significant $\mathrm{pH}$ reduction $(p<0.05)$ and among them, doses were significantly different too $(p<0.01)$. For LpS13 and LpM15, all doses induced a significant reduction of $\mathrm{pH}$ when compared to control samples $(p<0.001)$; however, no differences were observed between the doses $10^{4}$ and $10^{5} \mathrm{CFU} / \mathrm{g}$ ( $p=0.581$ and 0.842 , for LpS13 and LpM15, respectively). Comparing the performance of the different strains, no differences in $\mathrm{pH}$ were observed among them after $24 \mathrm{~h}$ of fermentation $(p>0.05)$. After 3 days of fermentation, the $\mathrm{pH}$ reached by LpS13 and LpM15 when inoculated at $10^{5} \mathrm{CFU} / \mathrm{g}$ was significantly lower to that observed in case of LpAv and LpA3 $(p<0.05)$. For the dose of $10^{5} \mathrm{CFU} / \mathrm{g}$, differences were observed among all L. plantarum strains $(p<0.05)$. Finally, for the highest dose assessed, differences were observed between LpM15 and $\operatorname{LpAv}(p=0.002)$ and LpA3 $(p=0.006)$. Furthermore, $\mathrm{pH}$ values of the silages after 30 days of fermentation were: $3.84 \pm 0.04$ for the control, $3.86 \pm 0.17,3.87 \pm 0.12,3.81 \pm 0.15$, and $3.81 \pm 0.01$, for L. plantarum LpAv, $3.88 \pm 0.01,3.88 \pm 0.02$, $3.88 \pm 0.02$, and $3.87 \pm 0.02$, for L. plantarum LpA3, $3.87 \pm 0.03$, $3.89 \pm 0.02,3.89 \pm 0.04$, and $3.90 \pm 0.05$, for L. plantarum LpS13 and $3.86 \pm 0.02,3.87 \pm 0.05,3.89 \pm 0.04$, and $3.89 \pm 0.02$, for L. plantarum LpM15, for the inoculation rates of $10^{4}, 10^{5}, 10^{6}$, and $10^{7} \mathrm{CFU} / \mathrm{g}$, respectively. Differences were not significant in any case $(p>0.05)$. In terms of counts of total LAB in MRS agar, after 30 days of ensiling, it was observed that the higher the inoculation rate, the lower the total counts observed (Figure 5).

\section{Crossed-Fermentation Capacity of $L$. plantarum Strains in Different Forages}

Lactiplantibacillus plantarum LpAv, LpA3, LpS13, and LpM15 were able to grow in all laboratory-prepared forage-based liquid media (OBM, ABM, SBM, MBM), and all strains induced significant reductions in $\mathrm{pH}$ in a reasonable similar manner. In this context, their fermentative capacity was further studied in oat, lucerne, sorghum, and maize silages. Results of $\mathrm{pH}$ counts of total LAB and yeasts and molds are displayed in Table 3. In case of lucerne and sorghum silage, total counts on MRS on the day of inoculation (day 0), were significantly higher (ca. $1 \log$ order $\mathrm{CFU} / \mathrm{g}$ ) than the total counts in control (noninoculated) samples, suggesting that the difference was due to the counts of the L. plantarum strains inoculated. In oat and maize silages, epiphytic LAB at the beginning of the ensiling process (day 0), reflected by total counts on MRS agar, overcame 

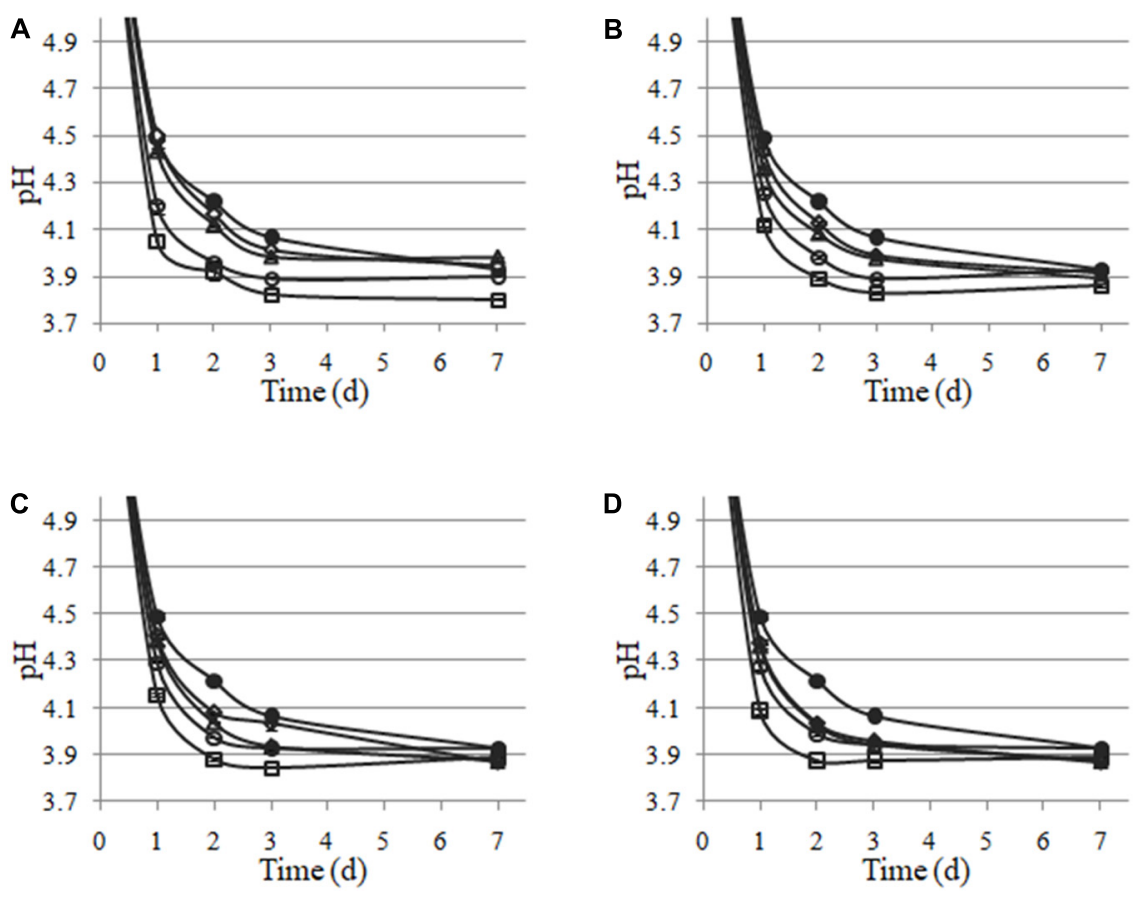

FIGURE 4 | pH values of maize-silage uninoculated (-) and inoculated with L. plantarum LpAv (A), LpA3 (B), LpS13 (C), and LpM15 (D), to an initial concentration of $10^{4}(\diamond), 10^{5}(\Delta), 10^{6}(\bigcirc)$, or $10^{7} \mathrm{CFU} / \mathrm{g}(\mathbf{\square})$.Values are means $( \pm \mathrm{SD})$ of three repetitions.

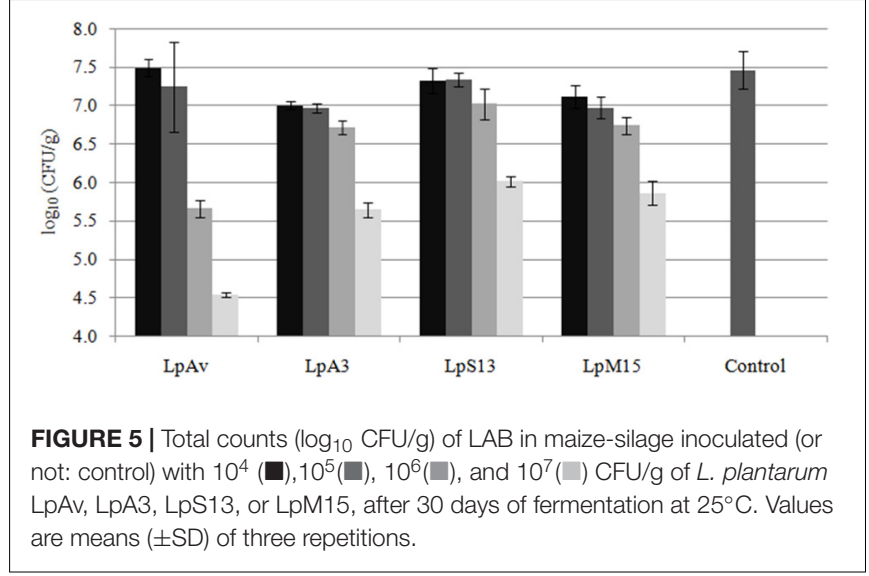

the concentration of the inoculated L. plantarum strains used by more than $1 \log$ cycle.

\section{Oat Silage}

After 2 days of fermentation, LpAv and LpM15 silages showed a significantly higher $(p=0.001$ and 0.038 , respectively) count of total $\mathrm{LAB}\left(\Delta \log _{10} \mathrm{CFU} / \mathrm{g}=2.37 \pm 0.09\right.$ and $2.26 \pm 0.03$, respectively) compared to control $\left(\Delta \log _{10} \mathrm{CFU} / \mathrm{g}=2.15 \pm 0.02\right)$. Moreover, significant lower $\mathrm{pH}$ was observed for LpAv, LpS13, and LpM15 silages compared to control samples. LpS13 and LpM15 were also effective for the early reduction of yeasts and molds.
Considering chemical analyses (Table 4), after 30 days of fermentation, ADF (\%) and NDF (\%) were significantly lower ( $p=0.026$ and 0.030 , respectively) in LpM15 silage ( $33.37 \pm 1.39$ and $52.20 \pm 2.02 \%)$ compared to control (35.53 \pm 0.47 and $55.18 \pm 0.40 \%)$.

\section{Lucerne Silage}

Although there were no significant differences in LAB counts between inoculated and control lucerne silage after 3 days of fermentation, the use of LpAv, LpA3, and LpS13 significantly decreased $\mathrm{pH}$, compared to control samples $(p<0.05)$. In particular, LpAv also kept the $\mathrm{pH}$ significantly lower after 30 days (Table 3). All strains were able to significantly reduce the counts of yeasts and molds, compared to control. Furthermore, the ammonia-N content in LpAv (3.10 $\pm 0.73 \%)$, LpA3 (3.53 $\pm 0.47 \%), \operatorname{LpS13}(4.38 \pm 0.09 \%)$, and LpM15 silages $(4.68 \pm 0.06 \%)$ were lower than for the untreated silages $(6.53 \pm 0.46 \%)$ after 30 days. LpM15 produced a significantly lower DM (32.32 $\pm 0.45 \%)$ than control $(33.33 \pm 0.45 \%)$ (Table 5).

\section{Sorghum Silage}

The total LAB counts $\left(\log _{10} \mathrm{CFU} / \mathrm{g}\right)$ in silages inoculated with all strains were significantly higher than in control samples. In addition, all four strains reduced the $\mathrm{pH}$ significantly faster than control. After $24 \mathrm{~h}$ the $\mathrm{pH}$ values were $4.20 \pm 0.01$ (LpAv, $p<0.001), 4.29 \pm 0.05$ (LpA3, $p<0.001), 4.26 \pm 0.13$ (LpS13, $p<0.001), 4.16 \pm 0.02(\mathrm{LpM} 15, p=0.000)$ and $4.71 \pm 0.04$ (control). After $72 \mathrm{~h}$ of fermentation, $\mathrm{pH}$ of inoculated samples was still significantly lower than control samples $(p<0.001$ in 
TABLE 3 | Crossed-fermentation capacity of selected L. plantarum strains in oat, lucerne, sorghum, and maize silages.

\begin{tabular}{|c|c|c|c|c|c|c|c|c|c|}
\hline \multirow{3}{*}{$\begin{array}{l}\text { Sample } \\
\text { Oat-silage }\end{array}$} & \multicolumn{6}{|c|}{ Cell count $\left(\log _{10} \mathrm{CFU} / \mathrm{g} \pm \mathrm{SD}\right)$} & \multicolumn{3}{|c|}{$\mathrm{pH}$} \\
\hline & \multicolumn{2}{|c|}{ Lactic acid bacteria } & \multicolumn{4}{|c|}{ Yeasts and filamentous fungi } & \multirow[b]{2}{*}{$t=0$ day } & \multirow[b]{2}{*}{$t=2$ days } & \multirow[b]{2}{*}{$t=30$ days } \\
\hline & $t=0$ day & $t=2$ days & $t=30$ days & $t=0$ day & $t=2$ days & $t=30$ days & & & \\
\hline Control & $7.04 \pm 0.04$ & $9.20 \pm 0.03^{a}$ & $8.07 \pm 0.01^{a}$ & $7.57 \pm 0.07$ & $4.89 \pm 0.46^{a}$ & $<2$ & $6.33 \pm 0.03$ & $4.25 \pm 0.03^{a}$ & $3.87 \pm 0.02^{a}$ \\
\hline LpAv & $7.15 \pm 0.04$ & $9.53 \pm 0.10^{b, c}$ & $8.15 \pm 0.13^{a}$ & $7.57 \pm 0.07$ & $4.62 \pm 0.17^{a, b}$ & $5.43 \pm 2.27$ & $6.33 \pm 0.03$ & $4.08 \pm 0.04^{b}$ & $3.89 \pm 0.02^{a}$ \\
\hline LpA3 & $7.18 \pm 0.05$ & $9.44 \pm 0.05^{b}$ & $7.99 \pm 0.10^{a}$ & $7.57 \pm 0.07$ & $5.12 \pm 0.39^{a}$ & $6.36 \pm 2.24$ & $6.33 \pm 0.03$ & $4.17 \pm 0.08^{a, b}$ & $3.89 \pm 0.02^{a}$ \\
\hline LpS13 & $7.19 \pm 0.08$ & $9.29 \pm 0.01^{a}$ & $8.16 \pm 0.06^{a}$ & $7.57 \pm 0.07$ & $3.70 \pm 0.05^{b, c}$ & $<2$ & $6.33 \pm 0.03$ & $4.05 \pm 0.04^{b}$ & $3.92 \pm 0.02^{a}$ \\
\hline LpM15 & $7.32 \pm 0.08$ & $9.58 \pm 0.03^{c}$ & $8.71 \pm 0.07^{b}$ & $7.57 \pm 0.07$ & $3.34 \pm 0.51^{c}$ & $<2$ & $6.33 \pm 0.03$ & $4.12 \pm 0.03^{b}$ & $4.01 \pm 0.04^{b}$ \\
\hline Lucerne-silage & $t=0$ day & $t=3$ days & $t=30$ days & $t=0$ day & $t=3$ days & $t=30$ days & $t=0$ day & $t=3$ days & $t=30$ days \\
\hline Control & $5.25 \pm 0.18^{a}$ & $9.61 \pm 0.12$ & $8.58 \pm 0.13^{a}$ & $5.07 \pm 0.21$ & $4.80 \pm 0.19^{a}$ & $2.60 \pm 0.30$ & $6.28 \pm 0.03$ & $5.49 \pm 0.24^{a}$ & $4.49 \pm 0.03^{a}$ \\
\hline LpAv & $6.64 \pm 0.21^{b}$ & $9.64 \pm 0.08$ & $6.65 \pm 0.17^{b}$ & $5.07 \pm 0.21$ & $4.20 \pm 0.23^{b}$ & $3.06 \pm 0.25$ & $6.28 \pm 0.03$ & $4.84 \pm 0.23^{b}$ & $4.39 \pm 0.03^{b}$ \\
\hline LpA3 & $6.41 \pm 0.18^{b}$ & $9.57 \pm 0.07$ & $6.55 \pm 0.25^{b}$ & $5.07 \pm 0.21$ & $4.51 \pm 0.23^{b}$ & $2.81 \pm 0.16$ & $6.28 \pm 0.03$ & $4.98 \pm 0.19^{a, b}$ & $4.45 \pm 0.04^{a, b}$ \\
\hline LpS13 & $6.47 \pm 0.21^{b}$ & $9.75 \pm 0.05$ & $7.30 \pm 0.25^{c}$ & $5.07 \pm 0.21$ & $4.04 \pm 0.17^{b}$ & $2.88 \pm 0.09$ & $6.28 \pm 0.03$ & $4.91 \pm 0.48^{a, b}$ & $4.42 \pm 0.06^{a, b}$ \\
\hline LpM15 & $6.66 \pm 0.18^{b}$ & $9.53 \pm 0.23$ & $7.03 \pm 0.15^{b, c}$ & $5.07 \pm 0.21$ & $4.29 \pm 0.11^{b}$ & $2.89 \pm 0.11$ & $6.28 \pm 0.03$ & $5.12 \pm 0.39^{a, b}$ & $4.46 \pm 0.03^{a, b}$ \\
\hline Sorghum-silage & $t=0$ day & $t=3$ days & $t=30$ days & $t=0$ day & $t=3$ days & $t=30$ days & $t=0$ day & $t=3$ days & $t=30$ days \\
\hline Control & $5.17 \pm 0.10$ & $8.78 \pm 0.05^{a}$ & $7.49 \pm 0.17^{a}$ & $5.33 \pm 0.02$ & $6.62 \pm 0.24^{a}$ & $4.29 \pm 0.02^{a}$ & $5.76 \pm 0.04$ & $3.89 \pm 0.03^{a}$ & $4.19 \pm 0.03^{a}$ \\
\hline LpAv & $6.78 \pm 0.08$ & $9.45 \pm 0.05^{b}$ & $<2.00$ & $5.33 \pm 0.02$ & $7.03 \pm 0.10^{b}$ & $4.50 \pm 0.15^{a, b}$ & $5.76 \pm 0.04$ & $3.67 \pm 0.01^{b, c}$ & $3.80 \pm 0.01^{b, c}$ \\
\hline LpA3 & $6.72 \pm 0.11$ & $9.48 \pm 0.01^{b}$ & $<2.00$ & $5.33 \pm 0.02$ & $6.98 \pm 0.03^{a, b}$ & $4.59 \pm 0.14^{b}$ & $5.76 \pm 0.04$ & $3.69 \pm 0.01^{b}$ & $3.84 \pm 0.02^{b}$ \\
\hline LpS13 & $6.40 \pm 0.01$ & $9.48 \pm 0.05^{b}$ & $<2.00$ & $5.33 \pm 0.02$ & $6.81 \pm 0.24^{a, b}$ & $4.70 \pm 0.10^{b}$ & $5.76 \pm 0.04$ & $3.64 \pm 0.01^{c}$ & $3.78 \pm 0.02^{c}$ \\
\hline LpM15 & $6.64 \pm 0.05$ & $9.32 \pm 0.02^{C}$ & $5.19 \pm 0.16^{b}$ & $5.33 \pm 0.02$ & $6.68 \pm 0.03^{a, b}$ & $4.66 \pm 0.11^{b}$ & $5.76 \pm 0.04$ & $3.70 \pm 0.01^{b}$ & $3.82 \pm 0.02^{b, c}$ \\
\hline Maize-silage & $t=0$ day & $t=1$ day & $t=30$ days & $t=0$ day & $t=1$ day & $t=30$ days & $t=0$ day & $t=1$ day & $t=30$ days \\
\hline Control & $7.82 \pm 0.08$ & $9.16 \pm 0.04$ & $7.05 \pm 0.12^{a}$ & $6.79 \pm 0.10$ & $\mathrm{Nd}$ & $3.86 \pm 0.26^{a, c}$ & $5.96 \pm 0.08$ & $4.37 \pm 0.02^{a}$ & $3.89 \pm 0.02^{a}$ \\
\hline LpAv & $8.21 \pm 0.12$ & $9.20 \pm 0.05$ & $6.52 \pm 0.08^{b}$ & $6.79 \pm 0.10$ & $\mathrm{Nd}$ & $5.23 \pm 0.17^{d}$ & $5.96 \pm 0.08$ & $4.17 \pm 0.02^{b}$ & $3.89 \pm 0.01^{a}$ \\
\hline LpA3 & $8.16 \pm 0.09$ & $9.09 \pm 0.04$ & $7.04 \pm 0.03^{a}$ & $6.79 \pm 0.10$ & $\mathrm{Nd}$ & $4.35 \pm 0.25^{b}$ & $5.96 \pm 0.08$ & $4.22 \pm 0.01^{b}$ & $3.88 \pm 0.01^{a}$ \\
\hline LpS13 & $8.27 \pm 0.01$ & $8.99 \pm 0.07$ & $6.68 \pm 0.02^{b}$ & $6.79 \pm 0.10$ & $\mathrm{Nd}$ & $4.50 \pm 0.04^{b}$ & $5.96 \pm 0.08$ & $4.19 \pm 0.04^{b}$ & $3.83 \pm 0.01^{b}$ \\
\hline LpM15 & $8.66 \pm 0.18$ & $9.09 \pm 0.08$ & $6.88 \pm 0.04^{a}$ & $6.79 \pm 0.10$ & $\mathrm{Nd}$ & $3.76 \pm 0.11^{c}$ & $5.96 \pm 0.08$ & $4.21 \pm 0.03^{b}$ & $3.89 \pm 0.01^{a}$ \\
\hline
\end{tabular}

Values are means $\left( \pm S D\right.$ ) of three repetitions. ${ }^{a, b, c}$ Values in columns with different superscripts differ significantly ( $\left.p<0.05\right)$. Nd, not determined.

all cases, compared to control). Furthermore, after 30 days of fermentation, inoculated silages displayed a $\mathrm{pH}$ lower than 3.84, while the $\mathrm{pH}$ of the control was above 4 . None of the strains were able to modify the chemical composition of silages after 30 days of fermentation, compared to control samples (Table 6).

\section{Maize Silage}

No differences were found in total LAB counts (CFU/g) among silos after $24 \mathrm{~h}$ of fermentation. However, the addition of $L$. plantarum strains significantly reduced $\mathrm{pH}$ after $24 \mathrm{~h}$ of ensiling. After 30 days of fermentation, $\mathrm{pH}$ values were lower than 3.90 in all cases, being the LpS13 silage the only one with a significantly lower $\mathrm{pH}$ value, compared to control. LpAv, LpS13, and LpM15 produced significantly lower ammonia-N content (4.56 \pm 0.05 , $4.51 \pm 0.30,4.91 \pm 0.10 \%$, respectively) compared to control $(5.83 \pm 0.11 \%)$, with no differences among inoculated silages (Table 7).

\section{Heterofermentative LAB}

\section{Selection of Heterofermentative LAB}

So as to select the strains with the highest potential to control yeasts and molds, the production of acetic acid was screened among the heterofermentative isolates obtained (results not shown). The strains producing the highest amounts of acetic acid were selected for further studies: L. brevis
LbB2 (6.39 $\pm 0.58 \mathrm{~g} / \mathrm{l})$, L. brevis LbM6 (6.89 $\pm 0.43 \mathrm{~g} / \mathrm{l})$, L. fermentum LfSY1 $(5.87 \pm 0.25 \mathrm{~g} / \mathrm{l})$, and L. fermentum LfM1 $(7.56 \pm 0.73 \mathrm{~g} / \mathrm{l})$. The concentrations of acetic acid produced by L. buchneri Ls141 and L. buchneri 463 were $5.42 \pm 0.36 \mathrm{~g} / \mathrm{l}$ and $5.30 \pm 0.53 \mathrm{~g} / \mathrm{l}$, respectively.

\section{Aerobic Stability in Maize-Silages}

After 90 days of fermentation, $\mathrm{pH}$ values ranged from 3.85 to 4.08. The $\mathrm{pH}$ of silages inoculated with Ls141, 463, and LfM1 were significantly higher $(p<0.05)$ than the control silages. For these strains, significant higher concentrations of acetic acid were observed, being 2.3 - three times higher than in control samples (Figure 6A). When silos were manufactured, DM ranged from $42.6 \pm 0.4 \%$ to $43.6 \pm 1.5 \%$, without significant differences ( $p>0.05)$ among samples. After 90 days of fermentation, $\mathrm{DM}$ ranged from $38.9 \pm 0.2 \%$ to $43.1 \pm 3.4 \%$, but again no significant differences were observed $(p>0.05)$ among treatments. Figure $6 \mathrm{~B}$ shows the $\Delta \mathrm{T}^{\circ} \mathrm{C}$ of the silos, exposed to the air after 90 days of fermentation, during $234 \mathrm{~h}$ (almost 12 days). Control samples lost aerobic stability $\left(\Delta \mathrm{T}>2^{\circ} \mathrm{C}\right)$ at the fastest rate (123 h, 5 days). In general, all strains under study were effective in conferring enhanced aerobic stability, with different capacity among them. The less effective strains were LbB2 (212 h, 8 days) and LfSY1 (224 h, 9 days), whereas the most effective ones were Ls141, 463, LfM1, and LbM6, which made silos stable at least for 12 days, when the experiment was stopped. 
TABLE 4 | Chemical analyses of oat-silage inoculated with L. plantarum isolated from oat (LpAv), lucerne (LpA3), sorghum (LpS13), and maize (LpM15) at the beginning and after 30 days of fermentation.

\begin{tabular}{|c|c|c|c|c|c|c|c|c|c|c|}
\hline Time (days) & Sample & DM (\%) & DM loss (\%) & CP (\%) & NDF (\%) & ADF (\%) & LDA (\%) & EE (\%) & Ash (\%) & N-NH3/NT (\%) \\
\hline$t=0$ & - & $20.18 \pm 0.30$ & - & $11.75 \pm 0.43$ & $63.94 \pm 0.37$ & $35.81 \pm 0.48$ & $5.16 \pm 0.24$ & $3.41 \pm 0.35$ & $18.25 \pm 0.43$ & $\mathrm{Nd}$ \\
\hline \multirow[t]{5}{*}{$t=30$} & Control & $19.72 \pm 0.46$ & $1.82 \pm 0.39$ & $11.80 \pm 0.46$ & $55.18 \pm 0.40^{a}$ & $35.53 \pm 0.47^{a}$ & $6.48 \pm 0.15$ & $3.77 \pm 0.27$ & $16.51 \pm 0.27$ & $0.93 \pm 0.29$ \\
\hline & LpAv & $19.37 \pm 0.24$ & $2.05 \pm 0.25$ & $11.60 \pm 0.42$ & $53.80 \pm 0.61^{a, b}$ & $34.63 \pm 0.21^{a, b}$ & $6.07 \pm 0.16$ & $3.22 \pm 0.06$ & $15.56 \pm 0.51$ & $1.25 \pm 0.29$ \\
\hline & LpA3 & $19.65 \pm 0.56$ & $1.95 \pm 0.28$ & $12.09 \pm 0.74$ & $55.12 \pm 1.78^{a, b}$ & $34.90 \pm 1.40^{a, b}$ & $6.38 \pm 0.08$ & $3.44 \pm 0.47$ & $14.35 \pm 2.82$ & $1.13 \pm 0.17$ \\
\hline & LpS13 & $19.56 \pm 0.56$ & $1.92 \pm 0.22$ & $11.69 \pm 0.46$ & $53.59 \pm 0.89^{a, b}$ & $34.10 \pm 0.37^{a, b}$ & $5.94 \pm 0.62$ & $3.56 \pm 0.28$ & $15.47 \pm 2.00$ & $0.99 \pm 0.20$ \\
\hline & LpM15 & $19.85 \pm 0.24$ & $1.61 \pm 0.50$ & $12.75 \pm 0.48$ & $52.20 \pm 2.02^{b}$ & $33.37 \pm 1.39^{b}$ & $6.27 \pm 1.01$ & $3.61 \pm 0.43$ & $17.35 \pm 1.96$ & $0.94 \pm 0.24$ \\
\hline
\end{tabular}

Dry Matter (DM), DM loss, Crude Protein (CP), Neutral Detergent Fiber (NDF), Acid Detergent Fiber (ADF), Acid Detergent Lignin (LDA), Ether Extract (EE), Ammonia Nitrogen/Total Nitrogen (N-NH3/NT). Values are means $( \pm S D)$ of three repetitions. ${ }^{a, b, c}$ Values in columns with different superscripts differ significantly $(p<0.05)$. Nd, not determined.

TABLE 5 | Chemical analyses of lucerne-silage inoculated with L. plantarum isolated from oat (LpAv), lucerne (LpA3), sorghum (LpS13), and maize (LpM15) at the beginning and after 30 days of fermentation

\begin{tabular}{|c|c|c|c|c|c|c|c|c|c|c|}
\hline Time (days) & Sample & DM (\%) & DM loss (\%) & CP (\%) & NDF (\%) & ADF (\%) & LDA (\%) & EE (\%) & Ash (\%) & N-NH3/NT (\%) \\
\hline$t=0$ & - & $32.86 \pm 0.31$ & - & $21.83 \pm 1.15$ & $37.78 \pm 1.35$ & $26.53 \pm 1.10$ & $6.81 \pm 0.30$ & $2.10 \pm 0.55$ & $12.00 \pm 0.98$ & $\mathrm{Nd}$ \\
\hline \multirow[t]{5}{*}{$t=30$} & Control & $33.33 \pm 0.45^{a}$ & $0.53 \pm 0.64$ & $20.17 \pm 1.40$ & $36.31 \pm 2.41$ & $27.95 \pm 3.44$ & $8.28 \pm 0.77$ & $3.69 \pm 0.82$ & $13.26 \pm 0.26^{a}$ & $6.53 \pm 0.46^{a}$ \\
\hline & LpAv & $33.19 \pm 0.72^{a}$ & $-0.59 \pm 0.60$ & $20.68 \pm 0.98$ & $35.33 \pm 0.65$ & $26.50 \pm 0.31$ & $7.41 \pm 0.10$ & $2.63 \pm 1.01$ & $12.49 \pm 0.42^{b}$ & $3.10 \pm 0.73^{b}$ \\
\hline & LpA3 & $33.64 \pm 0.34^{a, b}$ & $-0.30 \pm 0.58$ & $23.27 \pm 3.02$ & $36.38 \pm 1.80$ & $27.32 \pm 2.22$ & $7.87 \pm 0.45$ & $3.51 \pm 0.37$ & $12.82 \pm 0.20^{a, b}$ & $3.53 \pm 0.47^{b, c}$ \\
\hline & LpS13 & $33.01 \pm 0.31^{a, b}$ & $-0.66 \pm 0.62$ & $20.38 \pm 0.36$ & $35.95 \pm 1.21$ & $27.28 \pm 1.36$ & $7.96 \pm 0.06$ & $4.43 \pm 1.22$ & $13.18 \pm 0.14^{a}$ & $4.38 \pm 0.09^{c}$ \\
\hline & LpM15 & $32.32 \pm 0.45^{b}$ & $0.24 \pm 0.68$ & $20.02 \pm 0.83$ & $36.12 \pm 1.55$ & $30.87 \pm 7.40$ & $7.63 \pm 0.24$ & $3.52 \pm 1.32$ & $12.82 \pm 0.14^{a, b}$ & $4.68 \pm 0.06^{c}$ \\
\hline
\end{tabular}

Dry Matter (DM), DM loss, Crude Protein (CP), Neutral Detergent Fiber (NDF), Acid Detergent Fiber (ADF), Acid Detergent Lignin (LDA), Ether Extract (EE), Ammonia Nitrogen/Total Nitrogen (N-NH3/NT). Mean values $\pm S D$ are shown. Values are means $( \pm S D)$ of three repetitions. ${ }^{a, b, c}$ Values in columns with different superscripts differ significantly $(p<0.05)$. Nd, not determined. 


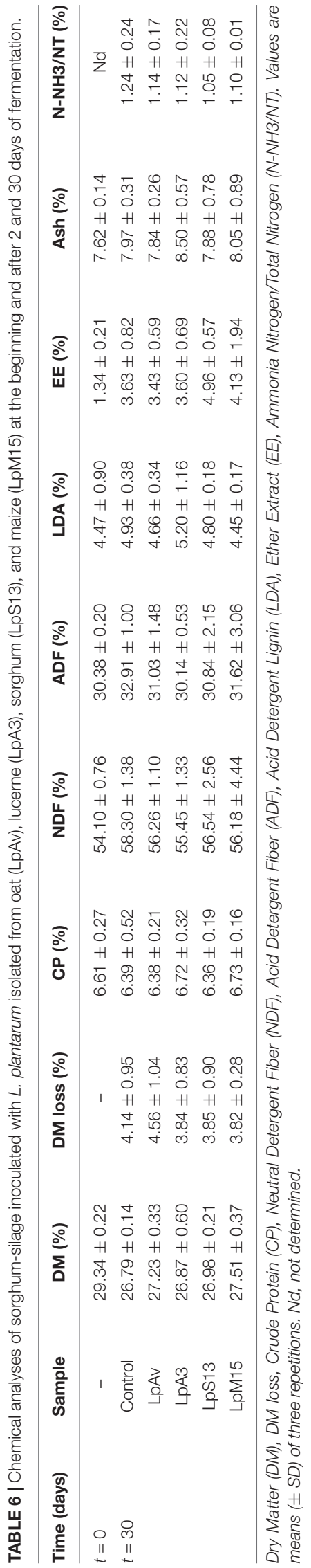

\section{DISCUSSION}

Epiphytic LAB widely vary in composition and numbers in plant materials $\left(10^{1}-10^{7} \mathrm{CFU} / \mathrm{g}\right)$, depending on many environmental factors (Pahlow et al., 2003). However, when favorable conditions of anaerobiosis, water activity, and temperature occur, spontaneous lactic acid fermentation may take place on the plant material, becoming LAB the dominants of the fermented substrate (Di Cagno et al., 2013). The strategy of inducing lactic fermentation to promote the growth of LAB has been largely used for the isolation of novel LAB candidates for their exploitation in forage fermentations, such as ensiling (Burns et al., 2018) and was the one used in this study. The homo- and hetero-fermentative species with the highest frequency of isolation were L. pentosus/plantarum and L. brevis, respectively.

Lactiplantibacillus plantarum is a species extensively used as inoculant for ensiling of lucerne (Filya et al., 2007; Zhao et al., 2020), sorghum (Thomas et al., 2013), maize (Dogi et al., 2013; Herrmann et al., 2015), ryegrass (Srigopalram et al., 2017; Muthusamy et al., 2020), and other forages (Ávila et al., 2010; $\mathrm{Ni}$ et al., 2015). In fact, L. plantarum is the most prevalent species in commercial inoculants (Fabiszewska et al., 2019). In our region, lucerne, oat, sorghum, and maize are the crops more frequently used for ensiling and then attention was focused on these crops. The growth ability of L. plantarum isolates was assessed in the same plant-based medium from which isolates were obtained (ABM, OBM, SBM, and MBM). Isolates obtained from the same plant material displayed different growth kinetics in laboratory-prepared media (FBM), indicating intrinsic diverse growth capabilities that justify strain screening. Considering that fast growth and acidification are of paramount importance for a microbial inoculants (Muck, 1988), L. plantarum LpAv, LpA3, LpS13, and LpM15 were selected for further studies after confirmation of their identity (partial 16S rRNA sequencing) and diversity (RAPD).

A common claim in commercial inoculants is that strains isolated from the same plant material where they are going to be used may perform better than strains isolated from other substrates (Weinberg, 1996). Crossed-growth kinetics and cell counts were performed for the four strains in OBM, ABM, SBM, and MBM. Considering the results obtained in a comprehensive way (growth kinetics, cell counts, and $\mathrm{pH}$ ), it was observed that growth capacity was related to the nature of the plant material rather than to the origin of the strain itself, confirming that for an homofermentative species as L. plantarum, inoculant's success depends on adequate substrate availability (Muck, 1988).

The fermentative capacity of the four L. plantarum strains were then assessed in maize, the main forage material use for ensiling in Argentina and worldwide (Weinberg and Ashbell, 2003; Khan et al., 2015), at four inoculation rates $\left(10^{4}, 10^{5}, 10^{6}\right.$, and $\left.10^{7} \mathrm{CFU} / \mathrm{g}\right)$. Fast acidification is a valuable characteristic for inoculants to preserve the silage by both inactivating plant proteases and reducing the growth of pathogenic and spoilage microorganisms (Dunière et al., 2013; Queiroz et al., 2018). Although statistical differences were observed for $\mathrm{pH}$ when strains were compared among them, these differences 


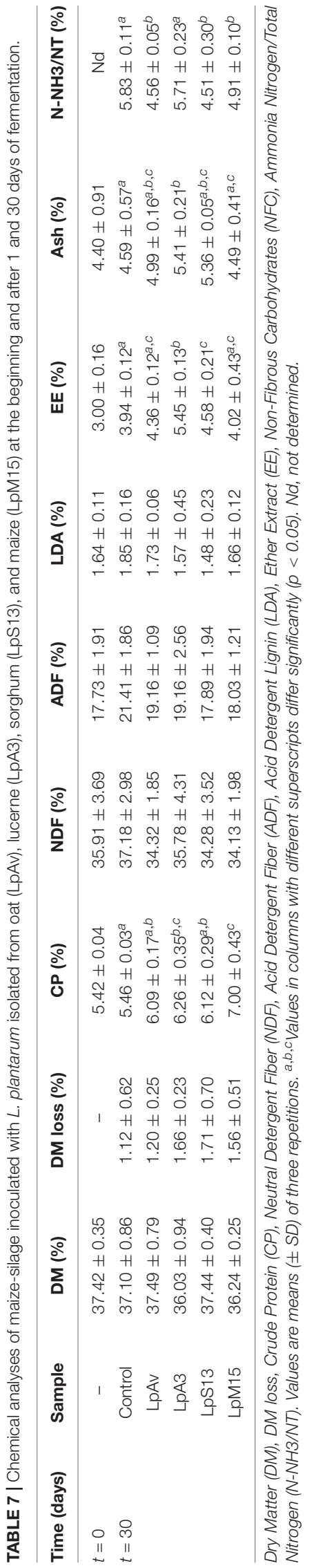

were negligible in terms of practical applications. The biggest magnitude of differences in $\mathrm{pH}$ were observed for the different doses rather than for the different strains. Therefore, and considering acidification capacity, it can be reasonable to assume that all four $L$. plantarum strains assessed were able to ferment maize in a reasonably similar manner. It is interesting to note that the lowest the inoculation rate, the higher the total counts of LAB observed after 30 days of fermentation. Our hypothesis, yet to be proved, is that extensive metabolic adaptation may have occurred when the lowest inoculation rate was used $\left(10^{4} \mathrm{CFU} / \mathrm{g}\right)$. This low inoculation rate certainly implied more duplication cycles until reaching the stationary phase, than an inoculation rate of $10^{7} \mathrm{CFU} / \mathrm{g}$. The latter concentration is closer to the one commonly reached by LAB at the stationary phase (ca. $10^{8} \mathrm{CFU} / \mathrm{g}$ ), then less duplication cycles are needed to reach the stationary phase, and in consequence less time is available to develop resistance due to exposure to environmental stresses. This adaptation is crucial for survival because it stimulates the production of additional energy and lowers the stress level, e.g., through alkalization of the cytosol under acidic conditions (Papadimitriou et al., 2016). These results also allow to confirm that the strains, even at the lowest inoculation rates, were able to dominate the fermentation by inhibiting the proliferation of epiphytic microbiota. For example, in samples inoculated with $10^{7} \mathrm{CFU} / \mathrm{g}$, total counts after 30 days of fermentation were fairly low, suggesting that the strains quickly reached the stationary phase, impairing the proliferation of the epiphytic microbiota, and entered the dead phase. In other words, the inoculated strains did not allow the growth of the epiphytic microbiota, as can be observed for control samples.

Considering that significant differences compared to control were observed for all strains for a dose of $10^{5} \mathrm{CFU} / \mathrm{g}$, and that inoculating at doses as high as $10^{7} \mathrm{CFU} / \mathrm{g}$ is economically not feasible (Oliveira et al., 2017), the dose of $10^{6} \mathrm{CFU} / \mathrm{g}$ was chosen for further studies. This dose was selected to ensure a proper fermentation since the epiphytic microbiota carried by different forage crops, or even by different harvests of the same plant material, may vary depending on several factors such as the type of plant, maturity of the crop, epiphytic bacteria content, and environmental factors like weather and harvesting conditions (Lindow and Brandl, 2003; Di Cagno et al., 2013).

Lactiplantibacillus plantarum LpAv, LpA3, LpS13, and LpM15, which were able to grow in all four FBM, were used to determine their fermentative capacity in oat, lucerne, sorghum, and maize silages.

LpS13, derived from sorghum, and LpM15, derived from maize, were effective strains for the acidification of oat silage and were both also able to control yeasts and molds. In addition, considering the reduction in ADF and NDF achieved by LpM15, as both chemical components are indirectly related to digestibility and DM feed intake, respectively, the reduction observed for these parameters could promote beneficial effects on animal performance (Meeske et al., 2002; Fulgueira et al., 2007). The level of epiphytic total LAB in the fresh plant material was close to that of the inoculated L. plantarum strains. Therefore, inoculated LAB could be potentially overwhelmed by the epiphytic population, 

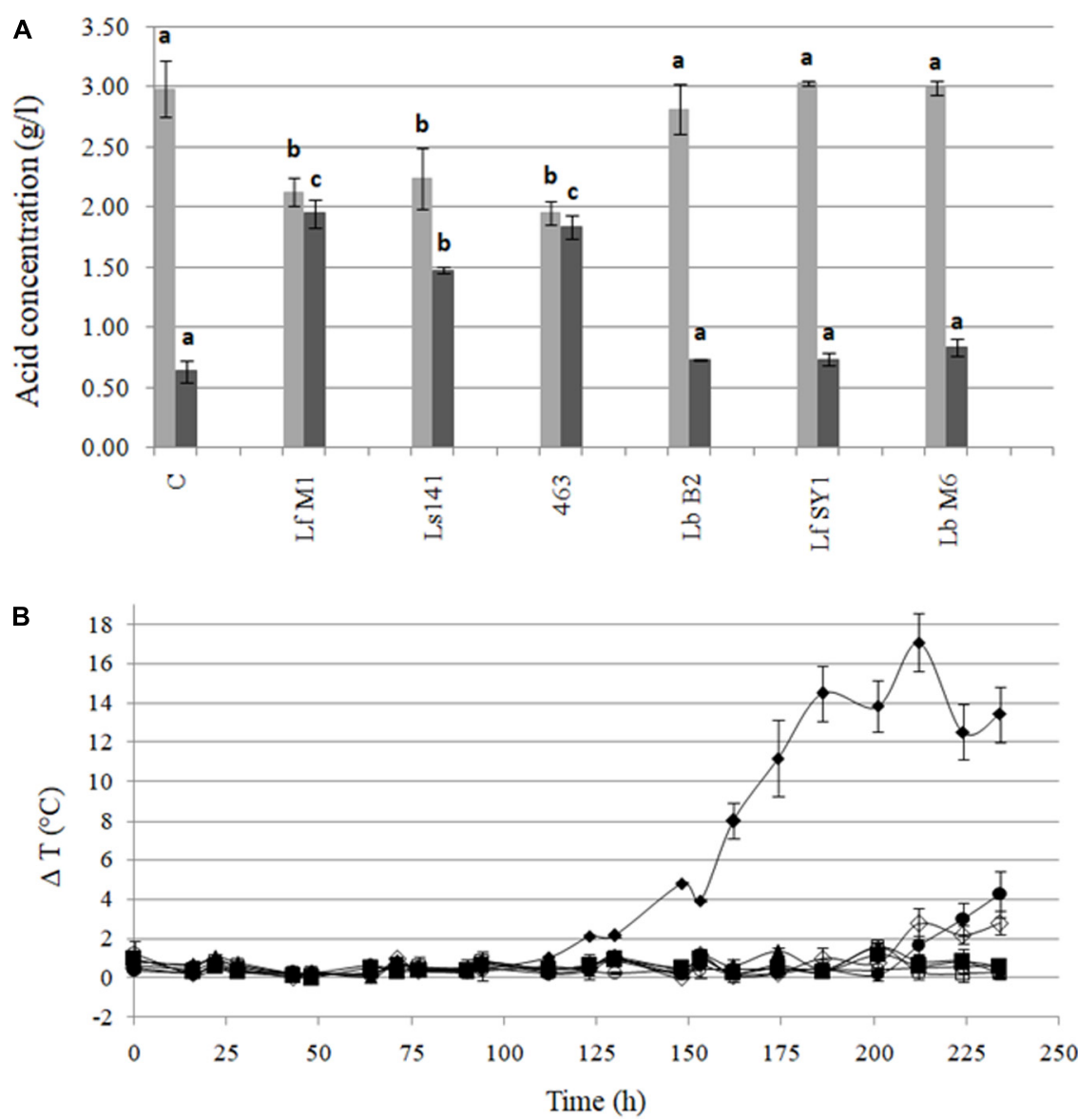

FIGURE 6 | (A) Lactic ( $\square$ ) and acetic ( $\square$ ) acid content ( $\mathrm{g} / \mathrm{l})$ of maize silage inoculated with heterofermentative strains after 90 days of fermentation. Values are means $( \pm \mathrm{SD})$ of three repetitions. ${ }^{a, b, c}$ Values with different letter differ significantly $(p<0.05)$ in each determined organic acid. (B) Aerobic stability $\left(\Delta \mathrm{T}^{\circ} \mathrm{C}=\mathrm{Tsilo}-\mathrm{Tambient}\right)$ of maize silages exposed to air after 90 days of fermentation. Untreated control ( $)$ and samples inoculated with $L$. buchneri 463 ( $\mathbf{\Lambda}$ ), L. buchneri Ls141 ( $\mathbf{\square}$ ), L. fermentum LfSY1 $(\bullet)$, L. fermentum LfM1 (○), L. brevis LbB2 $(\diamond)$, and L. brevis LbM6 $(\square)$. Values are means ( \pm SD) of three repetitions.

being this fact an additional challenge for the selected strains to dominate the fermentation (Filya et al., 2007). In spite of this challenge, the fermentation process was accelerated by the inoculation of LpAv, LpS13, and LpM15, and silage quality was improved by the latter.

The use of LpAv in lucerne silage significantly decreased $\mathrm{pH}$, and also kept the $\mathrm{pH}$ significantly lower after 30 days. Furthermore, the ammonia- $\mathrm{N}$ content was lower in all cases, compared to untreated silages, which can suggest less proteolysis and deamination rate. Particularly, the ammonia-N concentration was two times lower in LpAv silages compared to control. This parameter is generally used as an indicator of silage protein degradation (Whiter and Kung, 2001). The lower DM induced by LpM15 use, which might be due to a slow $\mathrm{pH}$ drop, is an unfortunate event as it could lead to a DM lost (Thomas et al., 2013). Ensiling lucerne may be challenging because of the low content of water-soluble carbohydrates and its high buffering capacity (Pang et al., 2011). However, L. plantarum has been successfully used over a wide range of $\mathrm{DM}, \mathrm{pH}$ values reported after fermentation ranged from 4.29 to 5.01 (Filya et al.,
2007; Ogunade et al., 2016). In general, the inoculation with homofermentative strains may render beneficial effects on the fermentation process (Whiter and Kung, 2001). In previous reports, a mean DM after ensiling, slightly lower than the initial mean value, was observed (Whiter and Kung, 2001; Rizk et al., 2005; Liu et al., 2016). This may occur when initial and final individual values are close among them. Then, the differences of the means may be negative, but not statistically significant, and so the loss of DM may look negative. When a difference is not statistically significant, then we cannot conclude that a negative loss of DM was indeed an increase of DM during ensiling, there was just preservation of DM.

In case of sorghum silages, after 30 days of fermentation, inoculated samples displayed a $\mathrm{pH}$ lower than the control group. Although inoculation did not modify the chemical composition of silages after 30 days of fermentation, compared to control samples, all L. plantarum strains improved the ensiling process, not only by accelerating the $\mathrm{pH}$ drop by day 3 , but by leaving a final $\mathrm{pH}$ significantly lower than control. Despite all strains were suitable for sorghum ensiling, significant amounts of viable LAB 
were found after 30 days of fermentation only when LpM15 was used. In a recent work (Alhaag et al., 2019), two L. plantarum strains were employed for sorghum silages (a commercial one and another isolated from sorghum) and, although both strains preserved the silages overall quality, the commercial strain was not found viable after 30 days of ensiling. Viable LAB in silages may display a potential probiotic role for ruminants (Acosta Aragon, 2012; Ellis et al., 2016; Fabiszewska et al., 2019), an hypothesis that needs further studies, then viability along storage may be considered a potential advantage.

It is generally considered that a fast decrease of $\mathrm{pH}$ close to 4.2 or less is adequate for maize preservation. These $\mathrm{pH}$ values are commonly achieved in the first hours of fermentation, even without the use of microbial inoculants, so there may not be too much room for accelerating the process (Nkosi et al., 2011). In this work, no differences were found in total LAB counts (CFU/g) among silos after $24 \mathrm{~h}$ of fermentation. However, the addition of L. plantarum strains significantly increased the rate of $\mathrm{pH}$ drop compared to control samples. All L. plantarum strains may be regarded as equally effective for decreasing the $\mathrm{pH}$ of maize silage. These results agreed with the previous dose-response assay in maize, in line with the in vitro to in situ correlation observed by Saarisalo et al. (2007). LpAv, LpS13, and LpM15 produced significantly lower ammonia-N content, compared to control samples. Similar to oat silage, these improvements in the nutritional value and $\mathrm{pH}$ decrease of the forage can be observed despite the fact that epiphytic LAB content in fresh maize was higher than the inoculation rate.

The performance of four L. plantarum strains isolated from oat, lucerne, sorghum, and maize was compared in these four plant materials, making all possible combinations, what we called crossed-fermentation. LpM15 derived from maize was the most effective strain for oat ensiling and would be the strain of choice for sorghum silage, whereas LpAv, isolated from oat, showed a better performance than the other strains in lucerne, both accelerating the $\mathrm{pH}$ drop and decreasing the proteolysis process. All L. plantarum strains may be regarded as equally effective for decreasing the $\mathrm{pH}$ of maize silage, but in particular LpAv, LpS13, and LpM15 produced significantly lower ammonia-N content, compared to control samples. Our results support the fact that the origin of the strain is of secondary importance, being its own ensiling capacity and the silage material characteristics what matters (Ávila et al., 2011).

Lentilactobacillus buchneri is presently the gold standard to promote aerobic stability in corn silage (Santos et al., 2013; Da Silva et al., 2014) or Napier grass (Guan et al., 2020). Acetic acid is one of the main organic acids produced by heterofermentative LAB and it has the capacity of promoting aerobic stability when silos are opened (Danner et al., 2003). L. brevis LbB2, L. brevis LbM6, L. fermentum LfSY1, and L. fermentum LfM1 were found to be the highest acetic acid producers.

Once silos are opened, fermented material is exposed to air and yeasts fermentation may occur. Aerobic stability is the capacity of silage in maintaining the sanitary and nutritive value of the ensiled forage for a longer period of time, in the presence of air. In our study aerobic stability was considered lost when the temperature of the ensiled material was $2^{\circ} \mathrm{C}$ above the room temperature (Burns et al., 2018). After 90 days of fermentation, the silages were well preserved, based on their $\mathrm{pH}$ and DM values. Control silages lost aerobic stability after 5 days of being exposed to air, followed by those inoculated with L. brevis LbB2 (8.8 days) and L. buchneri 463 (9.3 days), whereas the rest of the strains were effective in maintaining the inner temperature until the end of the assay (9.75 days). Although L. buchneri is the main species used in commercial inoculants to improve aerobic stability, some strains may produce biogenic amines, which is an undesirable characteristic (Nishino et al., 2007) that justify the research of other heterofermentative LAB (Muck et al., 2018). There are some reports which show that L. brevis enhanced the acetic acid content and aerobic stability of maize silages compared to control but less efficiently than L. buchneri (Danner et al., 2003; Acosta Aragón et al., 2012). Wild strains of Lactobacillus hilgardii were proposed for this aim too (Reis et al., 2017). On the other hand, there is limited evidence published about the possibility of using L. fermentum for enhanced aerobic stability (Adesogan et al., 2003). To the best of our knowledge, L. fermentum has never been employed in commercial inoculants as aerobic stability promoter in the southern cone. In this sense, the results of this study show a promising future for L. fermentum LfM1, among other isolates, to be used as silage inoculant for enhanced aerobic stability. This fact can contribute to the development of domestic inoculants to contribute to import substitution industrialization.

\section{CONCLUSION}

In this study the ubiquitous presence of LAB on 14 out of 15 plant materials analyzed was shown. From more than 100 isolates obtained, the application of a succession of experiments allowed us to narrow down the number of potential candidates of silage inoculants to two strains. Based on the studies performed, L. plantarum LpM15 and L. fermentum LfM1 displayed potential to be used as inoculants, however further studies are needed to determine their performance when inoculated together. The former because it positively influenced different quality parameters in oat, lucerne, sorghum, and maize silage, and the latter because of its capacity to confer enhanced aerobic stability to maize silage. The rest of the strains constitute a valuable collection of autochthonous strains that will be further studied in the future for new applications in animal or human foods.

\section{DATA AVAILABILITY STATEMENT}

The datasets presented in this study can be found in online repositories. The names of the repository/repositories and accession number(s) can be found in the article/Supplementary Material.

\section{AUTHOR CONTRIBUTIONS}

MP and GV designed the study, analyzed the data, and contributed to the writing of the manuscript. MP led all the 
experiments. JO was responsible for the HPLC analysis. $\mathrm{AB}$ and $\mathrm{MP}$ performed the molecular identification of the strains. MG and AM performed the chemical analyses. $\mathrm{GV}$ and $\mathrm{AB}$ participated in the revision of the manuscript and scientific discussions. All authors contributed to the article and approved the submitted version.

\section{FUNDING}

This research has been partially supported by the project PICT-2016-0256 "Desarrollo de biocultivos a partir de cepas autóctonas: hacia la autonomía en la producción tecnológica de microorganismos de interés en alimentos para humanos y animales," Agencia Nacional de Promoción Científica y Tecnológica, Argentina.

\section{REFERENCES}

Acosta Aragón, Y., Jatkauskas, J., and Vrotniakiene, V. (2012). The Effect of a Silage Inoculant on Silage Quality, Aerobic Stability, and Meat Production on Farm Scale. ISRN Vet. Sci. 2012, 1-6. doi: 10.5402/2012/345927

Adesogan, A. T., Salawu, M. B., Ross, A. B., Davies, D. R., and Brooks, A. E. (2003). Effect of Lactobacillus buchneri, Lactobacillus fermentum, Leuconostoc mesenteroides inoculants, or a chemical additive on the fermentation, aerobic stability, and nutritive value of crimped wheat grains. J. Dairy Sci. 86, 17891796. doi: 10.3168/jds.S0022-0302(03)73764-3

Alhaag, H., Yuan, X., Mala, A., Bai, J., and Shao, T. (2019). Fermentation characteristics of Lactobacillus plantarum and Pediococcus species isolated from sweet sorghum silage and their application as silage inoculants. Appl. Sci. 9:a9061247. doi: 10.3390/app9061247

Amaral, R. C., Carvalho, B. F., Costa, D. M., Morenz, M. J. F., Schwan, R. F., Ávila, C. L., et al. (2020). Novel lactic acid bacteria strains enhance the conservation of elephant grass silage cv. BRS Capiaçu. Anim. Feed Sci. Technol. 264:114472. doi: 10.1016/j.anifeedsci.2020.114472

Aragon, Y. A. (2012). "The Use of Probiotic Strains as Silage Inoculants," in Probiotics in Animals, ed. R. Everlon (London: IntechOpen), 1-32. doi: 10.5772/ 50431

Ávila, C. L. S., Schwan, R. F., Pinto, J. C., and Carvalho, B. F. (2011). "Potential use of native microorganisms strains of forage for silage production," in Proceedings of the II International Symposium on forage quality and conservation, (Piracicaba: ISFQ), 25-43.

Ávila, C., Valeriano, A., Pinto, J., Figueiredo, H., Rezende, A., and Schwan, R. (2010). Chemical and microbiological characteristics of sugar cane silages treated with microbial inoculants. Rev. Bras. Zoot. 39, 25-32. doi: 10.1590/ S1516-35982010000100004

Binetti, A., Suárez, V., Tailliez, P., and Reinheimer, J. (2007). Characterization of spontaneous phage-resistant variants of Streptococcus thermophilus by RAPD analysis and identification of phage-resistance mechanisms. Int. Dairy J. 17, 1155-1122. doi: 10.1016/j.idairyj.2007.01.007

Burns, P., Borgo, M. F., Binetti, A., Puntillo, M., Bergamini, C., et al. (2018). Isolation, characterization and performance of autochthonous spray dried lactic acid bacteria in maize micro and bucket-silos. Front. Microbiol. 9:1-11. doi: 10.3389/fmicb.2018.02861

Liu, C., Lai, Y. -J., Lu, X., Guo, P. -T., and Luo, H. -L. (2016). Effect of lactic acid bacteria inoculants on alfalfa (Medicago sativa L.) silage quality: assessment of degradation (in situ) and gas production (in vitro). J. Integrat. Agricul. 15:2834. doi: 10.1016/S2095-3119(16)61424-7

Da Silva, N. C., Dos Santos, J. P., Ávila, C. L. S., Evangelista, A. R., Casagrande, D. R., and Bernardes, T. F. (2014). Evaluation of the effects of two Lactobacillus buchneri strains and sodium benzoate on the characteristics of corn silage in a hot-climate environment. Grassland Sci. 60, 169-177. doi: 10.1111/grs.12053

\section{ACKNOWLEDGMENTS}

Melisa Puntillo is a doctoral fellow of CONICET. Authors are thankful to Roxana Paez (INTA EEA Rafaela) for discussing the experiments and providing samples and to Desiree Llorens (INLAIN, CONICET-UNL) for contributing to the lab-scale silage preparation.

\section{SUPPLEMENTARY MATERIAL}

The Supplementary Material for this article can be found online at: https://www.frontiersin.org/articles/10.3389/fmicb. 2020.586716/full\#supplementary-material

Supplementary Figure 1 | RAPD profiles with primers B10 and M13 for L. plantarum strains isolated from lucerne, oat, sorghum and maize. Positive control: L. plantarum Ls71.

Danner, H., Holzer, M., Mayrhuber, E., and Braun, R. (2003). Acetic acid increases stability of silage under aerobic conditions. Appl. Environ. Microbiol. 69, 562567. doi: 10.1128/AEM.69.1.562-567.2003

Di Cagno, R., Coda, R., De Angelis, M., and Gobbetti, M. (2013). Exploitation of vegetables and fruits through lactic acid fermentation. Food Microbiol. 33, 1-10. doi: 10.1016/j.fm.2012.09.003

Dogi, C. A., Fochesato, A., Armando, R., Pribull, B., de Souza, M. M. S., da Silva, et al. (2013). Selection of lactic acid bacteria to promote an efficient silage fermentation capable of inhibiting the activity of Aspergillus parasiticus and Fusarium gramineraum and mycotoxin production. J. Appl. Microbiol. 114, 1650-1660. doi: 10.1111/jam.12173

dos Santos Leandro, E., Ginani, V. C., de Alencar, E. R., Pereira, O. G., Rose, E. C. P., et al. (2020). Isolation, Identification, and Screening of Lactic Acid Bacteria with Probiotic Potential in Silage of Different Species of Forage Plants, Cocoa Beans, and Artisanal Salami. Probiot. Antimicrob. Proteins 2020:9679-y. doi: 10.1007/s12602-020-09679-y

Dunière, L., Sindou, J., Chaucheyras-Durand, F., Chevallier, I., and ThévenotSergentet, D. (2013). Silage processing and strategies to prevent persistence of undesirable microorganisms. Anim. Feed Sci. Technol. 182, 1-15. doi: 10.1016/ j.anifeedsci.2013.04.006

Edwards, U., Rogall, T., Blöcker, H., Emde, M., and Böttger, E. C. (1989). Isolation and direct complete nucleotide determination of entire genes. Characterization of a gene coding for 16S ribosomal RNA. Nucl. Acids Res. 17, 7843-7853. doi: 10.1093/nar/17.19.7843

Ellis, J. L., Bannink, A., Hindrichsen, I. K., Kinley, R. D., Pellikaan, W. F., Milora, N., et al. (2016). The effect of lactic acid bacteria included as a probiotic or silage inoculant on in vitro rumen digestibility, total gas and methane production. Anim. Feed Sci. Technol. 211, 61-74. doi: 10.1016/j.anifeedsci.2015.10.016

Fabiszewska, A. U., Zieliñska, K. J., and Wróbel, B. (2019). Trends in designing microbial silage quality by biotechnological methods using lactic acid bacteria inoculants: a minireview. World J. Microbiol. Biotechnol. 35, 1-8. doi: 10.1007/ s11274-019-2649-2

Filya, I. (2003). The effect of Lactobacillus buchneri and Lactobacillus plantarum on the fermentation, aerobic stability, and ruminal degradability of low dry matter corn and sorghum silages. J. Dairy Sci. 86, 3575-3581. doi: 10.3168/jds.S00220302(03)73963-0

Filya, I., Muck, R. E., and Contreras-Govea, F. E. (2007). Inoculant Effects on Alfalfa Silage: Fermentation Products and Nutritive Value. J. Dairy Sci. 90, 5108-5114. doi: 10.3168/jds.2006-877

Fulgueira, C., Amigot, S., Gaggiotti, M., Romero, L., and Basílico, J. (2007). Forage quality: Techniques for testing. Fresh Prod. 1, 121-131.

Giraffa, G., Andrighetto, C., Antonello, C., Gatti, M., Lazzi, C., Marcazzan, G., et al. (2004). Genotypic and phenotypic diversity of Lactobacillus delbrueckii subsp. lactis strains of dairy origin. Int. J. Food Microbiol. 91, 129-139. doi: 10.1016/S0168-1605(03)00368-4 
Guan, H., Ke, W., Yan, Y., Shuai, Y., Li, X., Ran, Q., et al. (2020). Screening of natural lactic acid bacteria with potential effect on silage fermentation, aerobic stability and aflatoxin B1 in hot and humid area. J. Appl. Microbiol. 128, 1301-1311. doi: 10.1111/jam.14570

Herrmann, C., Idler, C., and Heiermann, M. (2015). Improving aerobic stability and biogas production of maize silage using silage additives. Bioresour. Technol. 197, 393-403. doi: 10.1016/j.biortech.2015.08.114

Khan, N. A., Yu, P., Ali, M., Cone, J. W., and Hendriks, W. H. (2015). Nutritive value of maize silage in relation to dairy cow performance and milk quality. J. Sci. Food Agricul. 95, 238-252. doi: 10.1002/jsfa.6703

Kung, L., Shaver, R. D., Grant, R. J., and Schmidt, R. J. (2018). Silage review: Interpretation of chemical, microbial, and organoleptic components of silages. J. Dairy Sci. 101, 4020-4033. doi: 10.3168/jds.2017-13909

Lindow, S. E., and Brandl, M. T. (2003). MINIREVIEW Microbiology of the Phyllosphere. Appl. Environ. Microbiol. 69, 1875-1883. doi: 10.1128/AEM.69. 4.1875

Meeske, R., Van Der Merwe, G. D., Greyling, J. F., and Cruywagen, C. W. (2002). The effect of adding an enzyme containing lactic acid bacterial inoculant to big round bale oat silage on intake, milk production and milk composition of Jersey cows. Anim. Feed Sci. Technol. 97, 159-167. doi: 10.1016/S0377-8401(01) 00352-2

Muck, R. E. (1988). Factors Influencing Silage Quality and Their Implications for Management. J. Dairy Sci. 71, 2992-3002. doi: 10.3168/jds.S0022-0302(88) 79897-5

Muck, R. E., Nadeau, E. M. G., McAllister, T. A., Contreras-Govea, F. E., Santos, M. C., and Kung, L. (2018). Silage review: Recent advances and future uses of silage additives. J. Dairy Sci. 101, 3980-4000. doi: 10.3168/jds.201713839

Muthusamy, K., Soundharrajan, I., Srisesharam, S., Kim, D., Kuppusamy, P., Lee, K. D., et al. (2020). Probiotic characteristics and antifungal activity of Lactobacillus plantarum and its impact on fermentation of Italian ryegrass at low moisture. Appl. Sci. 10:a10010417. doi: 10.3390/app10010417

Ni, K., Wang, Y., Cai, Y., and Pang, H. (2015). Natural lactic acid bacteria population and silage fermentation of whole-crop wheat. Asian Australas. J. Anim. Sci. 28, 1123-1132. doi: 10.5713/ajas.14.0955

Nishino, N., Hattori, H., Wada, H., and Touno, E. (2007). Biogenic amine production in grass, maize and total mixed ration silages inoculated with Lactobacillus casei or Lactobacillus buchneri. J. Appl. Microbiol. 103, 325-332. doi: 10.1111/j.1365-2672.2006.03244.x

Nkosi, B. D., Meeske, R., Langa, T., and Thomas, R. S. (2011). Effects of bacterial silage inoculants on whole-crop maize silage fermentation and silage digestibility in rams. S. Afr. J. Anim. Sci. 41, 350-359.

Ogunade, I. M., Kim, D. H., Jiang, Y., Weinberg, Z. G., Jeong, K. C., and Adesogan, A. T. (2016). Control of Escherichia coli O157:H7 in contaminated alfalfa silage: Effects of silage additives. J. Dairy Sci. 99, 4427-4436. doi: 10.3168/jds.201510766

Ogunade, Ibukun, M., Queiroz, O. C. M., and Arriola, K. G. (2019). "Lactic Acid Bacteria and Silage Fermentation," in Lactic Acid Bacteria. Microbiological and Functional Aspects, 5th Edn, eds G. Vinderola, A. C. Ouwehand, S. Salminen, and A. von Wright (Florida: CRC Press), 275-285. doi: 10.1201/ 9780429057465-17

Oliveira, A. S., Weinberg, Z. G., Ogunade, I. M., Cervantes, A. A. P., Arriola, K. G., Jiang, Y., et al. (2017). Meta-analysis of effects of inoculation with homofermentative and facultative heterofermentative lactic acid bacteria on silage fermentation, aerobic stability, and the performance of dairy cows. J. Dairy Sci. 100, 4587-4603. doi: 10.3168/jds.2016-11815

Pahlow, G., Muck, R. E., Driehuis, F., Oude Elferink, S. J. W. H., and Spoelstra, S. F. (2003). "Microbiology of Ensiling," in Silage Science and Technology, eds D. R. Buxton, R. E. Muck, and J. H. Jarrison (Madison: American Society of Agronomy), 31-93. doi: 10.2134/agronmonogr42.c2

Pang, H., Qin, G., Tan, Z., Li, Z., Wang, Y., and Cai, Y. (2011). Natural populations of lactic acid bacteria associated with silage fermentation as determined by phenotype, $16 \mathrm{~S}$ ribosomal RNA and recA gene analysis. Systemat. Appl. Microbiol. 34, 235-241. doi: 10.1016/j.syapm.2010.10.003

Papadimitriou, K., Alegría, Á, Bron, P. A., de Angelis, M., Gobbetti, M., Kleerebezem, M., et al. (2016). Stress Physiology of Lactic Acid Bacteria. Microbiol. Mol. Biol. Rev. 80, 837-890. doi: 10.1128/mmbr.00076-15
Paradhipta, D. H. V., Lee, S. S., Kang, B., Joo, Y. H., Lee, H. J., Lee, Y., et al. (2020). Dual-purpose inoculants and their effects on corn silage. Microorganisms 8:8050765. doi: 10.3390/microorganisms 8050765

Queiroz, O. C. M., Ogunade, I. M., Weinberg, Z., and Adesogan, A. T. (2018). Silage review: Foodborne pathogens in silage and their mitigation by silage additives. 1, 4132-4142. doi: 10.3168/jds.2017-13901

Reis, C. B., Santos, A. O., Carvalho, B. F., and Schwan, R. F. (2017). Wild Lactobacillus hilgardii (CCMA 0170) strain modifies the fermentation profile and aerobic stability of corn silage. J. Appl. Anim. Res. 46, 1-7. doi: 10.1080/ 09712119.2017.1371609

Rizk, C., Mustafa, A. F., and Phillip, L. E. (2005). Effects of inoculation of high dry matter alfalfa silage on ensiling characteristics, ruminal nutrient degradability and dairy cow performance. J. Sci. Food Agricul. 85, 743-750. doi: 10.1002/jsfa. 2034

Saarisalo, E., Skyttä, E., Haikara, A., Jalava, T., and Jaakkola, S. (2007). Screening and selection of lactic acid bacteria strains suitable for ensiling grass. J. Appl. Microbiol. 102, 327-336. doi: 10.1111/j.1365-2672.2006.03103.x

Santos, A. O., Ávila, C. L., and Schwan, R. F. (2013). Selection of tropical lactic acid bacteria for enhancing the quality of maize silage. J. Dairy Sci. 96, 7777-7789. doi: 10.3168/jds.2013-6782

Schmidt, R. J., Hu, W., Mills, J. A., and Kung, L. (2009). The development of lactic acid bacteria and Lactobacillus buchneri and their effects on the fermentation of alfalfa silage. J. Dairy Sci. 92, 5005-5010. doi: 10.3168/jds.2008-1701

Srigopalram, S., Park, H. S., Ilavenil, S., Kim, D. H., Arasu, M. V., Kuppusamy, P., et al. (2017). Isolation, in vitro probiotic characterization of Lactobacillus plantarum and its role on Italian ryegrass silage quality enhancement. Int. J. Agricul. Biol. 19, 164-170. doi: 10.17957/IJAB/15.0260

Tanizawa, Y., Kobayashi, H., Nomura, M., Sakamoto, M., Arita, M., Nakamura, Y., et al. (2020). Lactobacillus buchneri subsp. silagei subsp. nov., isolated from rice grain silage. Int. J. Systemat. Evolution. Microbiol. 70:4138. doi: 10.1099/ijsem.0. 004138

Thomas, M. E., Foster, J. L., McCuistion, K. C., Redmon, L. A., and Jessup, R. W. (2013). Nutritive value, fermentation characteristics, and in situ disappearance kinetics of sorghum silage treated with inoculants. J. Dairy Sci. 96, 7120-7131. doi: $10.3168 /$ jds.2013-6635

Weinberg, Z. (1996). New trends and opportunities in the development and use of inoculants for silage. FEMS Microbiol. Rev. 19, 53-68. doi: 10.1016/01686445(96)00025-3

Weinberg, Z. G., and Ashbell, G. (2003). Engineering aspects of ensiling. Biochem. Engine. J. 13, 181-188. doi: 10.1016/S1369-703X(02)00130-4

Whiter, A. G., and Kung, L. (2001). The effect of a dry or liquid application of Lactobacillus plantarum MTD1 on the fermentation of Alfalfa Silage. J. Dairy Sci. 84, 2195-2202. doi: 10.3168/jds.S0022-0302(01)74666-8

Wuyts, S., Van Beeck, W., Allonsius, C. N., van den Broek, M. F., and Lebeer, S. (2020). Applications of plant-based fermented foods and their microbes. Curr. Opin. Biotechnol. 61, 45-52. doi: 10.1016/j.copbio.2019.09.023

Zhao, S. S., Wang, Y. P., Yang, F. Y., Wang, Y., and Zhang, H. (2020). Screening a Lactobacillus plantarum strain for good adaption in alfalfa ensiling and demonstrating its improvement of alfalfa silage quality. J. Appl. Microbiol. 129, 233-242. doi: 10.1111/jam.14604

Zheng, J., Wittouck, S., Salvetti, E., Franz, C. M. A. P., Harris, H. M. B., Mattarelli, P., et al. (2020). A taxonomic note on the genus Lactobacillus: Description of 23 novel genera, emended description of the genus Lactobacillus Beijerinck 1901, and union of Lactobacillaceae and Leuconostocaceae. Int. J. Syst. Evolution. Microbiol. 70, 2782-2858. doi: 10.1099/ijsem.0.004107

Conflict of Interest: The authors declare that the research was conducted in the absence of any commercial or financial relationships that could be construed as a potential conflict of interest.

Copyright (C) 2020 Puntillo, Gaggiotti, Oteiza, Binetti, Massera and Vinderola. This is an open-access article distributed under the terms of the Creative Commons Attribution License (CC BY). The use, distribution or reproduction in other forums is permitted, provided the original author(s) and the copyright owner(s) are credited and that the original publication in this journal is cited, in accordance with accepted academic practice. No use, distribution or reproduction is permitted which does not comply with these terms. 